\title{
WestVirginiaUniversity
}

THE RESEARCH REPOSITORY @ WVU

Graduate Theses, Dissertations, and Problem Reports

2012

\section{Expanding training opportunities for parents of children with autism}

Jennifer Lee Suppo

West Virginia University

Follow this and additional works at: https://researchrepository.wvu.edu/etd

\section{Recommended Citation}

Suppo, Jennifer Lee, "Expanding training opportunities for parents of children with autism" (2012). Graduate Theses, Dissertations, and Problem Reports. 181.

https://researchrepository.wvu.edu/etd/181

This Dissertation is protected by copyright and/or related rights. It has been brought to you by the The Research Repository @ WVU with permission from the rights-holder(s). You are free to use this Dissertation in any way that is permitted by the copyright and related rights legislation that applies to your use. For other uses you must obtain permission from the rights-holder(s) directly, unless additional rights are indicated by a Creative Commons license in the record and/ or on the work itself. This Dissertation has been accepted for inclusion in WVU Graduate Theses, Dissertations, and Problem Reports collection by an authorized administrator of The Research Repository @ WVU.

For more information, please contact researchrepository@mail.wvu.edu. 


\title{
EXPANDING TRAINING OPPORTUNITIES FOR PARENTS OF CHILDREN WITH AUTISM
}

\author{
Jennifer Lee Suppo \\ A dissertation submitted to \\ The College of Human Resources and Education \\ at West Virginia University \\ in partial fulfillment of the requirements of \\ the degree of \\ Doctor of Education \\ in \\ Special Education \\ Dr. Michael R. Mayton, Chair \\ Dr. Barbara Ludlow \\ Dr. Cathy Galyon Keramidas \\ Dr. Daniel Hursh \\ Dr. Katherine Mitchem \\ Morgantown, West Virginia \\ 2012 \\ Key Words: Autism, Parent Training
}




\section{ABSTRACT \\ Expanding Training Opportunities for Parents of Children with Autism \\ Jennifer Lee Suppo}

The purpose of this study was to demonstrate that parents who have children diagnosed with autism can obtain and apply knowledge of a research-based support for their children by utilizing a prescribed, self-directed, online program, giving families another possible method of obtaining training to help meet the discrepancy that exists between need and service. The design was a quasi-experimental, non-equivalent control group, pretest-posttest design that was used to test knowledge obtained from treatment. Additionally, the researcher examined parents' application of knowledge and perceptions regarding the treatment. The results demonstrate that parents who receive training using this method can obtain and apply knowledge of a researchbased support. Furthermore, participant feedback indicates parental support for this method of obtaining knowledge. The results suggest that using a self-directed, online program may serve to give families another possible method of obtaining informational training. Using this method of parental instruction may help fill a portion of the gap between the need for services and the lack of availability of services. Interventions based on the study could give parents the ability to act as their children's direct service provider to fulfill a part their intervention needs, especially when a family is facing a discrepancy between need and service. 


\section{ACKNOWLEDGEMENTS}

I would like thank the individual members of my committee who helped me come to the completion of my degree and to the beginning of a new career path. First, I want to give a special thank you to Dr. Mayton, my committee chair, for putting up with my "craziness" and steering me through this entire process. I want to thank Dr. Ludlow for accepting me into the program and believing in me. I want to thank Dr. Galyon-Keramidas who told me I could do this even when I believed I could not. I want to thank Dr. Hursh for his valuable input during my committee meetings. I also want to give thanks to Dr. Mitchem. She became my mentor during my Master's degree, encouraged me to obtain my doctorate, and has continued to guide into this new adventure.

To my husband of 18 years, Del Suppo, Jr., words cannot express my gratitude for all of the support you have provided me throughout our lives together, and yes, I am finally done with school! Thank you for being the husband and father you are. To my two beautiful daughters, Lauren "Angel Baby" and Rebecca "Becca Boo," thank you for being the wonderful, inspirational kids that you are. Lauren, your kindness to others and determination to be the best in all that you do inspires mom every day. Becca, you changed our family's life and made us stronger, all while you continue to amaze all of us every day. I could not ask for two better daughters and thank God everyday for blessing me with my beautiful family.

To my mom, Judy Mattozzi, my first mentor: you have continued to support me, mentor me, and above all else, love me. You showed me how to be both a mom and a teacher. To my brother, Jon Mattozzi, thank you for all of your love and support. Lastly, to my dad whose last words to me before he passed away several years ago were that he wanted to be here with me to see me obtain my doctorate. Well dad, you are. 


\section{TABLE OF CONTENTS}

Content

Page

Abstract.

ii

Acknowledgements. iii

Chapter I - Introduction.....

Introduction.

1

Family Challenges......

1

Support for Positive Outcome.

2

Statement of Problem........................................................... 4

Statement of Purpose.................................................. 5

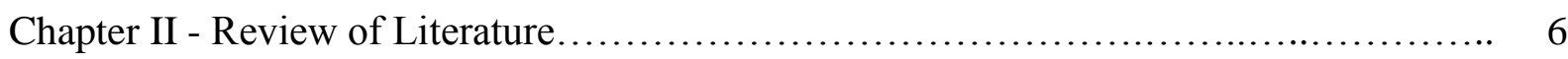

Home-Based Family-Centered Services................................ 7

Service Facility-Based Family-Centered Services........................... 13

Combination of Home and Service Facility Family-Centered Services............ 19

Alternative Training Services in Related Fields............................. 20

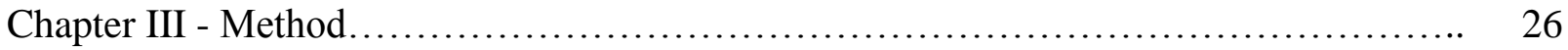

Research Questions..................................................... 26

Sampling ............................................................. 26

Description of Participants........................................... 27 


\section{Chapter III - Cont'd}

Description of Setting.................................................... 28

Research Design.................................................. 28

Experimental Controls................................................ 29

Treatment............................................................ 30

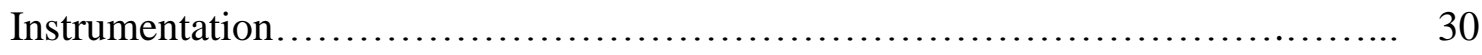

Data Collection.............................................................. 31

Data Analysis.................................................... 33

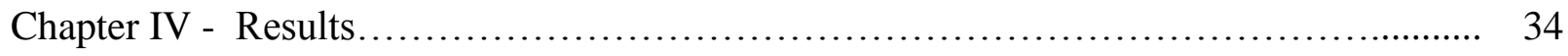

Research Questions................................................ 34

Description of Sample.............................................. 34

Parent Knowledge Results. ........................................... 38

Parent Application of Knowledge Results............................... 42

Parent Satisfaction Results.......................................... 45

Results Summary.................................................. 49

Chapter V - Discussion................................................... 50

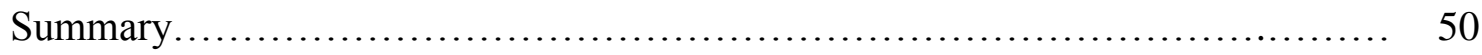

Conclusion............................................................. 53

Limitations....................................................... 54

Recommendations for Future Research................................ 55 


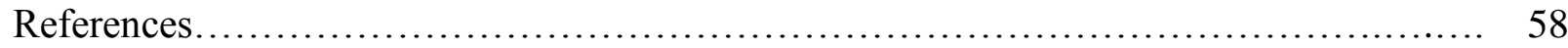

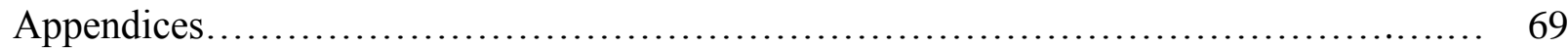

Appendix A........................................................ 70

Appendix B............................................................ 76

Appendix C ....................................................... 117

Curriculum Vitae.......................................................... 123 


\section{LIST OF FIGURES}

Figures

Page

Figure 1. Pretest and Posttest Participant Results Graph: Treatment Group.............. 39

Figure 2. Pretest and Posttest Participant Results Graph: Control Group............... 39

Figure 3. Treatment Groups Time to Complete Online Module...................... 41

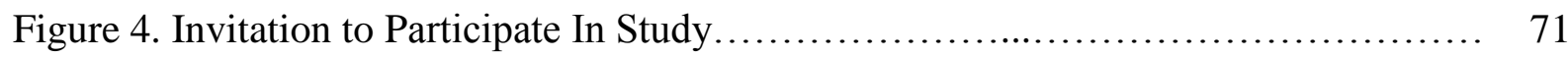

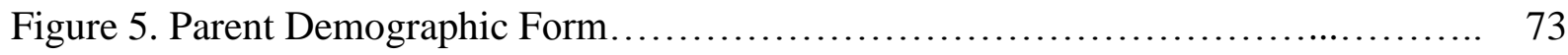

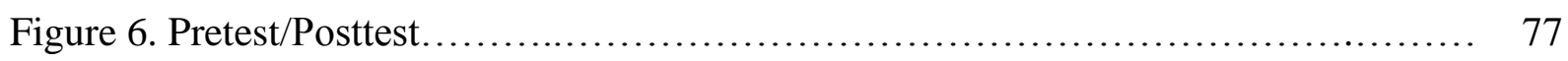

Figure 7. Parent Training Booklet.......................................... 89

Figure 8. Case Study for Visual Support Creation.............................. 106

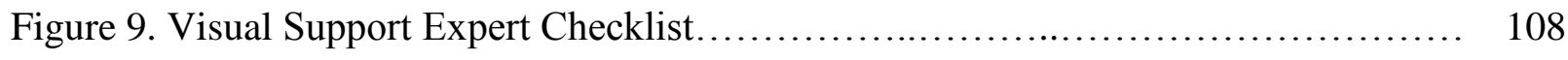

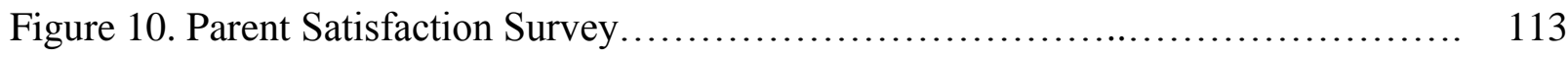




\section{LIST OF TABLES}

$\underline{\text { Tables }}$

Page

Table 1. Recruitment of Participants......................................... 35

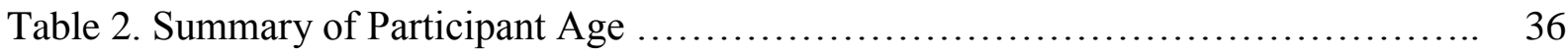

Table 3. Summary of Demographic Variables.................................. 37

Table 4. Summary of Visual Support Rubric.................................. 43

Table 5. Summary of Reviewers' Overall Visual Support Ratings................... 45

Table 6. Parent Survey Response........................................... 46

Table 7. Participant and Researcher Timeline.................................. 116

Table 8. Peer-Reviewed Articles Published Between 2001 and 2010.................. 118 


\section{CHAPTER I}

\section{Introduction}

The Centers for Disease Control and Prevention (2012) estimated that 1 out of every 88 children in the United States has autism. Autism is a developmental disability that is marked by impairments in the areas of social interaction, communication, and stereotypic behavior (American Psychiatric Association, 2000). Notably, 40\% of children diagnosed with autism do not talk (Centers for Disease Control and Prevention, 2012), and others perseverate on topics or items of interest (Dillenburger, Keenan, Gallagher, \& McElhinney, 2004). In addition, a number of children with autism face challenges in the area of reduced intellectual functioning and deficits with self-care (Dillenburger et al., 2004; Mahoney, Boyce, Fewell, Spiker, \& Wheeden, 1998), and, more commonly, associated difficulties with maintaining a regular sleep schedule (Dillenburger et al., 2004). These unique and varied social, communicative, and behavioral challenges are certain to bring on many challenges for families raising a child with autism.

\section{Family Challenges}

The associated challenges for families raising a child with autism take many forms. For instance, many families of children with autism face community and recreational restrictions because of their child's behavioral challenges (Dillenburger et al., 2004), which make even going out to a restaurant for a family dinner a difficult if not impossible undertaking. Additionally, parents of children with autism are pulled in different directions each day between having therapeutic staff invade the comfort and safety of their homes to becoming a shuttle service transporting their children between therapy sessions, specialized social groups and schools. These associated activities often leave little time for the activities in which many parents of typically developing children participate (e.g., baseball, soccer, and dance). Typically developing 
siblings' activities often have to take a backseat to the critical intervention therapies a child with autism needs in order to successfully function in society. With the parental demands of raising a child with autism, it is not surprising that siblings of children with autism often have feelings of neglect and resentment, and they have more behavior and emotional difficulties than their peers who do not have a sibling with autism (Dillenburger, Keenan, Doherty, Byrne, \& Gallagher, 2010; Petalas, Hastings, Nash, Lloyd, \& Dowey, 2009). In addition to these challenges, families can also face marital challenges. For example, the prevalence of divorce is significantly higher for parents who have a child with autism (Hartley et al., 2010). Spouses are often too busy with the aforementioned activities related to their children's needs to carve out any time for each other. For instance, even finding a sitter who can manage their children's unique needs is challenging. With all of these familial challenges, it is no wonder that parents of children with autism are shown to suffer more from stress than parents who have children with other special needs and parents of typically developing children (Hartley et al., 2010; Lecavalier, Leone, \& Wiltz, 2006; Schieve, Blumberg, Rice, Visser, \& Boyle, 2007). Moreover, researchers have found a connection between the severity of behavior of a child with autism and the presence of increased parental stress (Osborne \& Reed, 2009).

\section{Support for Positive Outcomes}

There are varieties of ways that families have found to cope with the difficulties associated with raising a child with autism. For example, researchers have found that some parents utilize social supports as a means of coping (Twoy, Connolly, \& Novak, 2007; Wang, Michaels, \& Day, 2011). Others have turned to religion as a means to cope with their child's disability (Wang et al., 2011) and find comfort or meaning regarding their child's disability through indentifying with a higher power or spiritual being. Moreover, some parents have found support from sharing 
the load with supportive spouses (Kuhaneck, Burroughs, Wright, Lemanczyk, \& Darragh, 2010). Having a child with autism who has unique behavioral challenges often isolates a family from the rest of the world, whereas, having a spouse who can share in the responsibility of raising such a child can alleviate some of the innumerable responsibilities and isolation that many parents (e.g., those who do not have a supportive spouse) feel when raising a child on their own. Equally important is that numerous studies have shown that many families successfully utilize the power of knowledge to cope with the difficulties, including the associated stress, of raising a child with autism (Dillenburger et al., 2004; Kuhaneck et al., 2010; Solomon, Ono, Timmer, \& Goodlin-Jones, 2008; Twoy et al., 2007).

This type of parent knowledge takes several forms, including knowledge of (a) their child's disability, (b) how to interact with their child, and (c) how to advocate for their child. Parental knowledge can effectively be increased in the form of parent training (Anan, Warner, McGillivary, Chong, \& Hines, 2008; Coolican, Smith, \& Bryson, 2010; Solomon et al., 2008; Vismara, Colombi, \& Rogers, 2009), and the National Research Council (2001) considers parent training an essential component of successful intervention programs for children with autism. Additionally, the Council found that it is critical to provide services for children with autism at a young age. In reality, many families of children diagnosed with autism face a discrepancy between need and service, including availability of training and support services for both child and parent (Applequist, 2009; Carbone, Behl, Azor, \& Murphy, 2010; Kalkbrenner et al., 2011; Montes, Halterman, \& Magyar, 2009; Thomas, Ellis, McLaurin, Daniels, \& Morrissey, 2007).

Researchers have explored ways to meet the discrepancy between need and service. Within that search, they have looked to families as a possible means to provide the critical, evidencedbased treatment their children often require. Researchers have found that parents can 
successfully provide treatment to their children diagnosed with autism once they have had parent training (Anan et al., 2008; Koegel, Symon, \& Koegel, 2002; Solomon, Necheles, Ferch, \& Bruckman, 2007). Moreover, researchers have established that parents cannot only provide treatment, but they can also be used to meet the discrepancy between need and service, if they have been provided with adequate, specialized training (Koegel et al., 2002; Nefdt, Koegel, Singer, \& Gerber, 2010; Stahmer \& Gist, 2001). However, discrepancies between need and service are still prevalent for children diagnosed with autism and their parents because not all families have access to parental training and the subsequent essential knowledge.

\section{Statement of Problem}

The application of evidence-based interventions at an early age has been shown to be effective in creating positive outcomes for children diagnosed with autism (Roger \& Vismara, 2008). Nevertheless, there remains a persistent discrepancy between need and available services for children diagnosed with autism and their families (Applequist, 2009; Carbone et al., 2010; Kalkbrenner et al., 2011; Montes et al., 2009; Thomas et al., 2007). Parents have been shown to be successful as the direct service provider to fulfill a part of their child's intervention needs (Anan et. al, 2008; Ingersoll \& Dvortcsak, 2006). However, many families face barriers because of their geographic location (Applequist, 2009, Mandell, Novak, \& Zubritsky, 2005), and still others face barriers to service needs because of a delay of services (Carbone et al., 2010). In order to improve the discrepancy between need and service delivery, alternative parent training options need to be explored because early intervention is critical to maximizing the academic, social, and behavioral success of these children (Woods \& Wetherby, 2003). 


\section{Statement of Purpose}

The purpose of this study was to demonstrate that parents who have a child diagnosed with autism could obtain and apply knowledge of a research-based support for their child by using a prescribed, self-directed, online program giving families another possible method of obtaining parent training. The researcher examined if parents utilizing such a program to learn how to create visual supports significantly increased their knowledge of this skill. Additionally, the researcher ascertained if parents were able to demonstrate an adequate application of their knowledge by creating an appropriate visual support. Lastly, the researcher obtained parental perceptions of using the prescribed, self-directed, online training program. 


\section{Chapter II}

\section{Review of Literature}

To understand how to meet the discrepancy between need and available services, the researcher conducted a review of the literature that addresses parent training of families with children diagnosed with autism. Although families of children with autism need and use a broad range of services (Thomas et al., 2007), access to these services are not equally available for all families. Symon (2001) examined the literature surrounding parent education for families of children with autism and discovered that there were discrepancies in providing services for families living in geographically distant locations. The discrepancy between need and available services was evident in 2001, and, 10 years later, a discrepancy between need and available services still exists (Applequist, 2009; Carbone et al., 2010; Kalkbrenner et al., 2011; Montes et al., 2009; Thomas et al., 2007).

During the past 10 years, new technologies have emerged that were not available in 2001, many of which are used to train and support special education teachers (Billingsley, Israel, \& Smith, 2011; Sebastian, Egan, \& Mayhew, 2009) and support the learning of children with disabilities (Smedley \& Higgins, 2005). In addition, the use of technology has been used to fill the shortage of unqualified special educators trained in autism spectrum disorders in rural areas by providing online training to these educators, who are needed to educate the growing number of children diagnosed with autism (Ludlow, Galyon-Keramidas, \& Landers. 2007). To begin the discussion of how to help meet the needs of families, especially families living in rural locations and families on long wait lists for services, a review of what has been done since 2001 is necessary to understand how to proceed in the future (see Table 8 in Appendix $\mathrm{C}$ for Table of Peer-Reviewed Articles Published Between 2001 and 2010). 
The main purpose of this literature review is to examine (a) current methods of parent training of parents of children with autism, and (b) alternative training services in related fields. A review of the literature will consist of the following themes:

1. Home-based, family-centered services

2. Service facility based, family-centered services

3. Combination of home and service facility-based, family-centered services

4. Alternative training services in related fields

\section{Home-Based, Family-Centered Services}

Parent outcomes. There is a plethora of published journal articles discussing the training of parents, and most of these studies utilize a slightly different training method. Even so, the main objective of each of these studies is to have parents serve as the facilitators of better learning outcomes for their children diagnosed with autism. Elder, Valcante, Won, \& Zylis (2003); Kashinath, Woods, \& Goldstein (2006); Nefdt et al. (2010); Nunes \& Hanline (2007); and Seung, Ashwell, Elder, \& Valcante (2006) all conducted parent training via interventionists within participants' homes. In these studies, each which utilized different parent training in terms of both technique and information provided, parents were able to gain adequate knowledge of the associated strategy or technique. For instance, in both Elder et al. and Seung et al., the interventionist trained fathers of children with autism in expectant waiting (i.e., the father prompts the child for a behavior and then waits a set amount of time for the desired behavior to occur) and imitating with animation techniques (e.g., when a child initiates a behavior the parent imitates the child with animated emphasis). In Elder et al., the interventionist taught parents by providing them with written handouts that described and provided examples of the strategy. Additionally, the interventionist modeled the strategy, which involved teaching a child a routine 
that was chosen prior to the intervention. Seung et al. taught fathers by videotaping father-child interactions, thus enabling fathers to review the videotape after training and implementation of learned techniques with their children. The fathers could then observe the skills in which they needed additional assistance. The studies were conducted during an 8-12 week and a 10-12 week time period, respectively. Even with this extensive time period, it would be difficult for individuals living in rural areas to receive similar intensity levels of training due to the pervasive lack of access to trained professionals (Applequist, 2009; Thomas et al., 2007).

Nunes and Hanline (2007) trained parents in naturalistic strategies including arranging the environment to make it more conducive to learning. Moreover, the interventionist in the study introduced the family to the use of a pictorial communication system that was incorporated into the child's intervention sessions. The researchers taught the strategies by instructing the parent in the appropriate techniques during the intervention sessions and by providing the parents with a written summary sheet of the techniques. Moreover, the intervention was taught and conducted in only two home visits.

The efficacy of parent training is further evidenced in Kashinath et al. (2006), in which it was demonstrated that parents increased the use of teaching strategies with their children after implementation of a 5-6 month parent training with the interventionist and a speech-language pathologist. Trainers met with parents 1 - 2 times per week during sessions that lasted from 60 to 90 minutes each. Parent training included instruction in naturalistic, routine-specific teaching strategies such as arranging the environment to promote child interactions and providing gestural/visual cuing to prompt the child's participation during routines. The interventionist trained parents by utilizing written handouts describing the protocol to follow during the selected routines, videotaping segments of other parents implementing the strategy, and modeling the 
appropriate techniques. Additionally, the interventions took place within the participant's home and were often conducted during the late afternoon/early evening hours to accommodate the family's preferences and work and/or school schedules.

Nefdt et al. (2010) trained the primary caregivers of twenty-seven children with autism. The authors utilized a self-directed learning program implementing the use of video instruction that lasted a total of 1 hour and 6 minutes in order to provide parents with introductory knowledge of an evidence-based method while they were waiting for services. The video taught the use of naturalistic intervention strategies from Pivotal Response Training (PRT), implemented with children to increase their verbalization. Additionally, parents were given an instruction manual that provided another layer of support for learning the strategies. PRT consists of children, within natural environments, learning using evidence-based instructional techniques that include the use of embedded reinforcers, and preparing a child for transitional changes, for example, by using visuals, such as pictures or words that show the order of a task and prompts the child needs to subsequently perform a activity (Koegel \& Koegel, 2006). The findings suggested that parents not only learned the techniques, but they also showed an increase in number of positive parent/child interactions. Moreover, the children in the study had a noted increase in verbalization. In all aforementioned studies, the parents were capable of obtaining and applying the knowledge to implement specific skills that utilized a variety of strategies, all of which were provided during varying amounts of time.

Child outcomes. Some studies have also demonstrated the effectiveness of training parents as agents for positive changes by measuring positive child gains (Moes \& Frea, 2002; Reagon \& Higbee, 2009; Schertz \& Odom, 2007; Tarbox, Schiff, \& Najdowski, 2010). Moes and Frea (2002) trained parents to facilitate appropriate functional communication. A clinician 
conducted a functional analysis of each child's inappropriate behavior during an initial visit and posited that all of the children utilized challenging behaviors to gain access to a preferred item or activity. Clinicians, who were at the family's home once or twice a week during the treatment phase, taught parents specific techniques to give their children an alternative means to gain access to desired items or activities, although the method of delivery used to teach parents the desired techniques was not clearly defined by the authors. All three children demonstrated a decrease in inappropriate behavior and an increase in appropriate functional communication.

Reagon and Higbee (2009) and Schertz and Odom (2007) each found positive child gains in measured behaviors. Reagon and Higbee showed that parents could be the implementer of procedural changes that produce positive outcomes for their children. In their investigation, parents were trained to create and implement scripts and script-fading procedures to help their children acquire appropriate vocalizations during play. Parents were trained using written script samples, modeling, prompting, and interventionist feedback. The results showed language gains for all three children in the study. Similarly, Schertz and Odom found that parents, who were taught joint attention intervention strategies, helped their children make significant gains in joint attention. Joint attention is a level of responding that consists of orienting eyes or head, in conjunction with another person, toward an object or person and is often seen as a precursor to future demonstrations of appropriate social reciprocity. Parents were trained by employing the use of a manual that provided written details for implementing joint attention intervention strategies as well as an oral overview of the strategies provided by the interventionists. The study also showed maintenance of the measured behavior during a 5-week, post-intervention maintenance measure. 
Tarbox et al. (2010) demonstrated that a parent could implement a successful behavioral change in the treatment of a child with a feeding disorder. The three-year-old boy with a diagnosis of autism had very selective eating habits. After a consultant taught the mother how to implement a non-removal of food procedure by prompting and praising the correct implementation of the strategies, the parent successfully implemented the procedure, and subsequent significant gains were shown in appropriate eating by the child. The consultant was present during the intervention phase for up to 5 hours a day for the first four meals. However, instruction and assistance depended on the consultant's schedule and availability, thus limiting the potential feasibility of using a similar intervention in areas that are less densely populated with and readily accessible to therapeutic service personnel (Carbone et al, 2010).

Parent satisfaction with outcomes. Schertz and Odom (2007) demonstrated the effectiveness of parents as agents for change after receiving training. Consequently, the study emphasized the increase in parents' confidence in helping their children. Additionally, it showed the potential of an intervention to help develop positive parent-child relationships. As a result, parents expressed an overall satisfaction with the intervention, and two out of three parents noted their children's progress because of the intervention. Similarly, other studies have shown a general parent satisfaction with results derived from their training and subsequent implementation of an intervention (Lucyshyn et al., 2007; Solomon et al., 2007).

Solomon et al. (2007) implemented a parent training utilizing the Floortime model. Trained consultants made monthly, half-day visits to families and instructed them using modeling and coaching, and the children made developmental gains. Further, of note is the high percentage $(90 \%)$ in overall satisfaction with the training program. The authors also noted the relationship between the number of hours parents spent working with their children and the 
outcome of the children's pre and post scores on the Functional Emotional Assessment Scale (FEAS). Plainly said, the more hours a parent spent working with his/her child, the higher the child's scores.

Similarly, Lucyshyn et al. (2007) found that the family of the child participating in the study approved of the intervention, noting the importance of the study and the flexibility that enabled family members to maintain their regular schedule and work at their own pace. Parents were trained by modeling, coaching, behavior rehearsal, and self-monitoring of the provision of appropriate supports that were based on a positive behavior support plan created from a functional behavioral assessment. Researchers conducted maintenance measures of appropriate child behaviors at 6 months and 7 years after the conclusion of the parent-implemented positive support plan. There was a measurable change in positive child behaviors, but this change could have been the result of maturation. However, it should be noted that the parents acknowledged a better quality of life for the family and a decrease in family isolation associated with their child's increase in positive child behaviors, which they attributed to the intervention.

Even with the positive outcomes of family-based, home intervention and training, the reality is that with challenging work schedules and children's time in school settings and other activities, not all families can be served in the home, especially when expected to accommodate the availability of professionals who serve as in-home parent trainers. Although studies have demonstrated the effectiveness of training parents as agents for positive changes and parental satisfaction with in-home services, there was only one home-based study identified in this review that utilized technology to reach out to families who experienced barriers to receiving parent training. Nefdt et al. (2010) provides one possible technology-based method for reaching families living in geographically distant areas, or those who are on long wait lists for services. 
Their method of delivering parent training through the self-directed use of video instruction makes use of technology that can be implemented within the home and enables families to selfmonitor their participation in training without the burden of having to find caregivers in order to attend training sessions elsewhere (e.g., at a clinic). Although other studies have utilized this form of technology, it was not used to directly address the discrepancy between need and available services. Video for parent training was also used in the aforementioned Elder et al. (2003) and Kashinath et al. (2006) studies. In addition to video instruction, Nefdt et al. employed the use of a manual to provide families with an additional layer of informational support. This type of parental training and support was also used in the previously noted studies by Elder et al., Kashinath et al., Nunes and Hanline, Reagon and Higbee, and Schertz and Odom. The Nefdt et al. procedure would permit families to receive training in their own homes and at their own pace, thereby eliminating the need to travel long distances for training or accommodate a professional's limited availability. Home-based services are one common method utilized to train parents of children with autism. Another method of providing parent-family-centered services is utilizing the service facility-based approach to parent training.

\section{Service Facility-Based, Family-Centered Services}

Parent outcomes. Many studies that research service facility-based, family-centered services for families of children diagnosed with autism focus on parental outcomes (Ingersoll \& Dvortcsak, 2006; Koegel et al., 2002; Stahmer \& Gist, 2001; Symon, 2005; Vismara, Colombi et al., 2009; Whittingham, Sofronoff, Sheffield, \& Sanders, 2009). Stahmer and Gist (2001) examined twenty-two families enrolled in a twelve-week parent education program. Parents were trained on PRT techniques. Moreover, half of the families participated in an additional twelveweek parent support group. Parents, who worked one-on-one with a trainer, also received a 
supplementary manual, providing them with additional instructional support that could be accessed at home between sessions. The data showed that parents with support from a parental support group performed the technique better than the parents who were only in the twelve-week education program. Furthermore, the children of the parents who met the criteria for performance did significantly better than the children of the parents who did not meet the performance criteria, showing that educators may also have to find ways to motivate parents and demonstrate to them the importance of family participation in their child's progress.

Koegel et al. (2002) and Symon (2005) evaluated parents' implementation of PRT. Koegel et al. researched the effect of a 25 hour training, conducted across 5 hours a day for 5 consecutive days, to help families living in geographically distant areas. Parent trainers consisted of both doctoral students in special education and clinical psychologists. The trainers instructed parents in the use of proper PRT techniques, utilizing a combination of discussion, modeling, and observation with feedback. Subsequently, families were provided with a training manual to be utilized at home. The data showed an increase in the parent's use of appropriate PRT techniques. Similarly, Symon found that parents, when provided with a 25 hour training across 5 hours a day for 5 consecutive days, could successfully learn to implement PRT procedures. The trainers, as in the abovementioned study, provided parents instruction on proper usage of PRT techniques that employed a combination of discussion, modeling, and observation with feedback. In addition, as with the Koegel et al. study, families were provided with a training manual for an additional layer of assistance. Additional data were collected on spread of effect of the training techniques used in this study, and researchers concluded that parents could train other significant caregivers of the child diagnosed with autism to use the PRT techniques. 
Ingersoll and Dvortcsak (2006) examined the effects of a nine-week, once per week parent training. The focus of the training was teaching families naturalistic techniques to increase their children's social and communicative interactions. The researchers provided parent training for the first two sessions, and teachers led the subsequent sessions. The training took the form of videotaped examples, group discussion, and problem solving. Additionally, participants were given written assignments to be completed at home. The researchers administered a pretest and posttest on the information taught during the training. The posttest data showed an average increase in parent knowledge on the procedures from $29 \%$ to $75 \%$.

Vismara, Colombi,et al. (2009) conducted a twelve-week, 1 hour per week brief parent training using techniques from PRT and the Early Start Denver Model (ESDM). Eight families of children with autism participated in the clinic-based study. Trainers provided parents with a training manual containing ten strategies chosen from ESDM and PRT and used this manual as a guide during training. Trainers also provided additional modeling and instruction. The children showed a significant increase in functional verbal utterances and imitative behaviors as a result of the parent training on and implementation of the techniques.

Whittingham et al. (2009) conducted a randomized, controlled trial on the effects of parent training. The parent training consisted of teaching parents positive parenting principles, and although the methods for instructional delivery during the group sessions were not clearly defined by the authors, the individual parent sessions with the instructor consisted of instructor observation with practice and feedback. Moreover, parents were taught how to use visual supports such as Social Stories @ and Comic Strip Conversations @ (Gray, 1994a, 1994b). Parents in the parent-training group were less over-reactive to their children's behavior when compared to the parents in the wait list group. Moreover, the researchers noted that parents in the 
parent training group were less verbose when working with their children than the parents in the wait list group. Furthermore, it was concluded that when parents learn positive techniques to help their children, they could assist in producing socially significant, positive child outcomes.

Child outcomes. When parents serve as the primary agents for positive change they can help produce significant, positive outcomes for their children diagnosed with autism (Anan et al., 2008; Koegel et al., 2002; Laugeson, Frankel, Mogil, \& Dillon, 2009; Solomon et al., 2008; Symon, 2005; Whittingham et al., 2009). Koegel et al., Stahmer and Gist, Symon, and Whittingham et al. not only show that parents are capable of learning techniques through parent training, but they also demonstrate that the children participating in the studies had improved skill and behavioral outcomes. Children were shown to have significant improvements in problematic behaviors (Symon, 2005; Whittingham et al., 2009) and verbalization skills (Koegel et al., 2002; Stahmer \& Gist, 2001). Other studies show similar improvements in positive child outcomes (e.g., Anan et al., 2009; Laugeson et al., 2009; Solomon et al., 2008).

In Anan et al. (2008), parents were trained in behavioral principles over the course of one, 12-hour initial training workshop and subsequent 12-week training. The behavioral therapist trainers used modeling and coaching with feedback to train the parents to use intervention procedures such as reinforcement, prompting, and behavioral momentum. Children participating in the study made gains in both language and communication, with the largest gains evidenced in adaptive behavior skills demonstrating that the participants made significant developmental gains at a much faster rate than demonstrated prior to the implementation of the treatment.

Solomon et al. (2008) demonstrated significant child gains in the areas of adaptive functioning and improvements in transitions, after training parents to give positive attention and praise for appropriate behaviors and ignore inappropriate behaviors. Additionally, there were 
noted improvements with the child's willingness to share preferred items with others. During the introductory sessions, clinicians provided direct support to the parents by telling them what to say to their children. However, as the trainings progressed, the clinician took more of a support role by reinforcing appropriate parent-child interactions.

Laugeson et al. (2009) implemented a randomized, controlled study with a delayed treatment group focusing on teenagers and their parents. Parents were taught to help their teenagers overcome everyday obstacles, such as difficulty socializing with peers, which is a common difficulty with individuals diagnosed with autism. Parent training was in the form of instruction on appropriate verbal and electronic communication with peers. The teens in the treatment group were shown to have an increased knowledge of social skill etiquette and a better quality of friendships when compared to the delay treatment group.

Parent satisfaction with outcomes. Many of the aforementioned studies examined parental satisfaction with the effects of training (Anan et al., 2008; Ingersoll \& Dvortcsak, 2006; Koegel et al., 2002; Solomon et al., 2008; Whittingham et al., 2009). Koegel et al. (2002) trained parents living in geographically distant areas, and these parents reported that they subsequently had more occurrences of positive interactions with their children. Anan et al. examined the outcome of a 12-week training that educated parents on the implementation of behavioral principles, such as reinforcing appropriate behavior, and Wittingham et al. (2009) examined the outcome of a 9-week program teaching parents positive parenting principles. Both studies demonstrated an overall parent satisfaction with the training programs, including satisfaction with a reduction in parental stress as well as improved outcomes for children. Solomon et al. educated parents in positive parenting principals such as positive attention and praise in a twophase, 6-week session. The authors reported that parents found their children's behaviors less 
distressing after participating in the parent training. Overall, most parents report that they are pleased with their participation in these types of service facility-based, family-centered training programs, especially in the areas of child increases in appropriate behaviors.

The parent training studies conducted at a service facility demonstrated that parents could gain adequate knowledge from parent training, could serve as the agent for significant positive outcomes for their children, and were typically satisfied with parent training outcomes. Each study provided parents training on a variety of interventions utilizing different methods of delivery, including the use of modeling (Anan et al., 2008; Koegel et al., 2002) and written manuals that provide additional parent training support (Koegel et al., 2002; Stahmer \& Gist, 2009; Symon, 2005; Vismara, Columbi et al., 2009). Though service facility-based parent training services tend to produce positive outcomes for children diagnosed with autism and their parents, there are still barriers to meeting the needs of those in geographically distant locations and those on long wait lists for services. Koegel et al. (2002) and Vismara, Columbi et al. (2009) examined ways to reduce the barriers to receiving parent training. Although the parents in Koegel et al. reported that after participating in parent training they had more occurrences of positive interactions with their child, the parents traveled from geographically distant areas for a training that lasted for 5 consecutive days. This method of providing parent training would not be feasible for every family. Barriers such as careers, needs of siblings, lack of financial resources, and other familial obligations would make this type of training prohibitive. Vismara, Columbi et al. demonstrated the parents could learn information, that when implemented, provided positive change for their children. However, the study was conducted at a clinic and over a 12 -week period, producing barriers similar to those already discussed. Additional studies have been 
conducted utilizing a combination of service facility-based and home-based, family-centered services to train parents of children with autism.

\section{Combination of Home and Service Facility, Family-Centered Services}

Brookman-Frazee (2004) and Peishi (2008) discuss the effects of parent training that was both home and service facility-based. The authors in both studies found that parents were more responsive to their children after the intervention. For example, parents responded more appropriately to their children's behavior, and they were more aware of their children's needs. In Peishi, parent training was based on the principles of applied behavior analysis (ABA) and included lectures, handouts, videotaped instruction, role-play and group discussions. The training combined 16 hours of group training with 4 hours of home visitation by a clinician. Parents in this study were also more accepting of their children with autism after receiving parent training. For instance, parents were less critical of their children's behavior.

Brookman-Frazee (2004) trained two of the parents in their home, and the third parent received training in both the home and in a clinic. Parents were trained in PRT using either clinician led sessions or a parent-clinician partnership. The clinicians prompted the parents to use appropriate PRT strategies that were based on the manual on PRT. The researchers compared the differences between sessions that were clinician-led versus sessions that were parent-led and found that in sessions led by the parent, the child was appropriately engaged more often, and the parent was observed to be less stressed than when the session was clinician-led. Interestingly, there were no notable differences in the outcomes among the three families participating in the study.

Coolican, et al. (2010) examined the efficacy of conducting a brief parent training utilizing PRT to meet the needs of families who were on a long wait list for services. The study 
consisted of a 6-hour training utilizing PRT and was conducted in both a clinical setting for group sessions and home settings for individual sessions. The researchers demonstrated that parents, through a relatively brief training, gained the necessary knowledge to produce positive child gains in functional verbal utterances and appropriate behavior. Additionally, parents found both the training, which was presented through modeling the appropriate PRT techniques, and the accompanying manual very helpful, and overall found the experience to be positive. Coolican et al., Brookman-Frazee (2004), and Peishi (2008) utilized multiple locations to deliver training to parents (e.g., home and clinic) and several methods to present the information to parents (e.g., modeling, lectures, video, manuals, etc.) to successfully train them in the use of strategies to help their children with autism.

In the real world, there are persistent barriers to parents and children receiving the services they so desperately need. How can researchers develop training to reach those who are on a long wait list or are geographically distant from services? To answer this question, the literature surrounding related service fields was examined to find how the gap between informational needs and deficits in available services has been bridged by presenting information through alternative methods of informational delivery.

\section{Alternative Training Services in Related Fields}

Finding solutions to bridge the gap between services and poor availability of services in rural areas is an issue in many service fields, and many areas of education and social services are looking towards technology for solutions (Coe \& Youn, 2008; Gibson, Pennington, Stenhoff, \& Hopper, 2010; Ludlow et al., 2007; Smith \& Meyen, 2003; Zahn \& Buchanan, 2002).

Researchers need to look at how family-centered services are currently implemented and how other areas of educational and social services are bridging the gap between rural and urban 
communities. For instance, Coe and Youn (2008) found that there has been increased usage of distance education in the area of social work. Online instruction and live desktop videoconferencing can be effectively used in many areas of education for teacher preparation, consultation, and professional development, as well as in promoting school-home communications and helping parents gain knowledge about their child's disability (Gibson et al., 2010; Smith \& Meyen, 2003). Studies show that technology can be used to successfully train teachers to work with children with autism (e.g., Ludlow et al., 2007; Zahn \& Buchanan, 2002). Zahn and Buchanan (2002) were able to use video of the children with whom the teachers worked to help the teachers assess challenging behaviors. Researchers have found that distance learning can be as equally effective as live instruction (Vismara, Young, Stahmer, Griffith, \& Rogers, 2009). Technology can aid in documenting the behavior of a child with autism and make that documentation accessible to specialists nationally and internationally to shorten diagnosis turnaround and improve diagnostic accuracy (Reischl \& Oberleitner, 2009). The use of technology can be cost-effective and one way to bridge the gap between services and the rural availability of services (Ludlow et al., 2007; Reischl \& Oberleitner, 2009; Rule, Salzberg, Higbee, Menlove, \& Smith, 2006; Smith \& Meyen, 2003). Related service fields have utilized technology as an alternate method of providing parents with training and information (Mandel, Bigelow, \& Lutzker, 1998; Nefdt et al., 2010; Pacifici, Delaney, White, Nelson, \& Cummings, 2006; Sanders, Calam, Durand, Liversidge, \& Carmont, 2008; Sharry, Guerin, Griffin, \& Drumm, 2005).

Sharry et al. (2005) successfully examined the use of video instruction within a clinical setting to train parents of children with behavioral and developmental difficulties. Video and web-delivered parent training has also been utilized within the home environment (Mandel, et 
al., 1998; Nefdt, et al., 2010; Pacifici, et al., 2006; Sanders, et al., 2008). Mandel et al. (1998) showed that parents could learn safety skills by watching a self-directed video within their homes. Additionally, Pacifici et al. (2006) showed that foster families could utilize a selfdirected, web-based program to increase parent knowledge on successfully meeting their child's behavior challenges. Moreover, Sanders et al. demonstrated that families could utilize selfdirected, web-based supports to enhance intervention effects of a television-based program designed to help parents improve their children's behaviors. Although by today's standards the study conducted by Connell, Sanders, \& Markie-Dadds (1997) may seem dated, the researchers' method of self-directed, parent training (provided to families whose children had behavioral difficulties and lived in rural areas) utilized a manual similar to the aforementioned parent training autism study conducted by Nefdt et al. (2010) and Connell et al. also incorporated a weekly telephone conversation with the participants to inquire about their progress and to prompt them to continue to progress through the materials. Hudson et al. (2003) also used a self-directed training approach (using informational booklets, manuals and videotapes) to teach parents who had children with intellectual and behavioral difficulties how to manage their children's behavior. The program was available to parents through either group support (e.g., a therapist facilitated the training with a group of parents using the materials) or telephone support (e.g., a therapist provided phone support to troubleshoot any difficulties the parents were having with the materials), and parents could also obtain the training through self-direction (e.g., the parents were provided the information through regular mail and guided themselves through the training materials). The researchers found that parents participating in the self-directed group learned as much information as the parents who were in the groups that received assistance from therapists. 
Advances in technology have made the use of Internet-based support more easily accessible for families. Richards and Alvarenga (2002) delivered Internet-based training modules to adults with panic disorders. The modules were designed to help adults reduce the severity of their symptoms by learning strategies to cope with their disorder. Similarly, Carpenter, Frankel, Marina, Naihua, and Smalley (2004) provided training that utilized the Internet to deliver training modules on behavioral techniques, such as conflict resolution, so that parents of teens with Attention Deficit Hyperactivity Disorder could help their children reduce behavioral difficulties. The flexibility of this program enabled participants the freedom to work through the modules within the framework of the families' busy lives. Moreover, Parette, Meadan, Doubet, \& Hess (2010) found that parents of children with disabilities not only utilize the Internet to obtain information on their children's disability, but also a majority of the parents $(65 \%)$ wanted more information on Internet sites that could provide information on their children's disability. Self-directed training (Nefdt et al., 2010) and the utilization of Internetbased informational support (Parette et al., 2010) have also been examined by researchers for use with families of children with autism.

In reviewing the literature surrounding parent education, one constant principle arises: Parent training tends to lead to better outcomes for both parent and child. The literature establishes parents as effective mediators for positive change for their children in social, emotional, communicative and behavioral domains. Additionally, many of the studies indicate that families participating in parent training increase positive parent-child interactions and reduce parental stress. Furthermore, parents tend to be satisfied with the effects of parent training. However, despite these documented positives, there is limited literature on how to reach parents and children who do not have access to these services because they either live in a 
geographically distant area or are on a long wait list for services. Moreover, the aforementioned studies demonstrate that parents can learn a variety of complex skills (e.g., arranging the environment, visual strategies, behavioral principles) through a range of methods of training delivery (e.g. manuals, lectures, live modeling, video modeling, etc.) and with multiple layers and types of training support (e.g., a manual and modeling of the skill). Internet-based parent training is just another layer of support utilizing the same training techniques as in earlier, less technologically advanced studies. For example, a training manual can be viewed online, and video modeling can be utilized to model techniques for any given training and made available to parents using a computer.

As evidenced by the research in this review, alternative methods to provide parent training to families who are living in geographically distant areas or are on a long wait-list for services need to be explored utilizing new technologies that were not available to the general population ten years ago. Parents with children with disabilities are already utilizing web-based support to obtain information on their child's disability (Parette et al., 2010), and there is now an opportunity to harness this technology and thereby direct parents through the maze of information by providing direction and support. With the difficulties in receiving services that parents often face, these technologies should be examined as a possible way to bridge this gap. Parents of children with autism need to have access to services in order to meet the specialized needs of their families (Meadan, Halle, \& Ebata, 2010), yet parents are having difficulty accessing these services (Dymond, Gilson, \& Myran, 2007; Montes et al., 2009). With the wider availability of new technologies, training can be provided to parents who experience barriers that prevent ready access to needed services and supports. 
Although there is limited research in the use of self-directed training within the area of autism, the success of self-directed delivery models within other human service fields has opened the possibility of using this method. Additionally, there is support for providing parents with information using self-directed, web-based support, and, as the literature demonstrates, many families are already searching online for information on their child's disability. However, families need to be guided through the maze of available information so as to be directed to and through the use of evidence-based practices. The discrepancy between need and service for a family with a child diagnosed with autism makes searching for information and training alternatives a necessity. Within the treatments that are available to families of children with autism, researchers have found that using evidence-based practices (for example, using schedules or story-based interventions) is an effective approach in helping children with a diagnosis of autism (National Autism Center, 2009; Rogers \& Vismara, 2008)

The current study will examine the outcome of using a self-directed, online program to provide training in visual supports to parents of children with autism. Additionally, the researcher will measure if the prescribed use of the training method produces significant gains in parent knowledge. Furthermore, the researcher will examine if parents are able to adequately apply their knowledge. Last, the researcher will obtain parental perceptions of using this type of training program. 


\section{CHAPTER III}

\section{Method}

\section{Research Questions}

Main Research Question: What will be the outcomes of using a self-directed, online program to provide training in visual supports to parents of children with autism?

Sub-questions:

(a) Does the prescribed use of the training method produce significant gains in parent knowledge of visual supports?

(b) Are parents able to demonstrate an application of their knowledge by creating an appropriate visual support?

(c) What are parental perceptions of using a prescribed, self-directed, online parent-training program?

\section{Sampling}

I conducted purposeful sampling of the participants who had known similarities to the desired target population, for example, families who had children with autism and were facing a discrepancy between need and available services. I used purposeful sampling because random sampling would have required numbers of participants well beyond the manageable scope and time frame of the study, especially given the potential number of children diagnosed with autism within a given area. Participation was by invitation. Participant recruitment was conducted through three venues. I advertised in doctor's offices, a support group for autism and through local educational agencies. Invitations were sent out in Western Pennsylvania in an area that all three venues overlapped. I selected this area because it is predominately rural and the 
surrounding counties are rural (The Center for Rural Pennsylvania, 2010) and because families living in this area tend to face discrepancies between need and service (Kohler,1999). The researcher accepted families living outside of the predefined area when they met a set of predetermined inclusionary criteria (see Figure 4 in Appendix A for the Invitation to Participate in the Study). The inclusionary requirements for participation involved parents who (a) had a child diagnosed with autism, (b) read above a sixth grade level, (c) did not participate in any formalized parent training on the use of visual supports, (d) were either on a waiting list for services or lived in a rural area and/or perceived that they have had difficulty being able to attend a parent training or receive training on one or more topics of interest concerning their child with autism because of the availability or lack of availability of services, and (e) had access to a computer with an Internet connection (see Figure 5 in Appendix A for the Parent Demographic Form that was used to verify that participants can read above a sixth grade level. The participant demographic form is written at a grade 7.4 reading level, as verified by the Flesh-Kincaid Grade Level Formula, and participants' correct adherence to the form's directions provided a reasonable method of screening for reading level.)

\section{Description of Participants}

The participants were the primary caretakers of children diagnosed with autism. This was verified by a written acknowledgement by the parents on the parent demographic form. Participants were identified as those able to read and understand the learning modules. Additionally, participants had not previously engaged in any formalized parent training programs on visual supports. Furthermore, the parents were on a wait list for services at the time of the intervention or lived in a rural county, and/or perceived that they have had difficulty being able to attend a parent training or receive parent training on one or more topics of interest concerning 
their child with autism because of the availability or lack of availability of services. Moreover, parents had ongoing access to a computer and an Internet connection. Information confirming that the participants met the inclusionary criteria was collected using a participant demographic form (see Figure 5 in Appendix A for Parent Demographic Form).

\section{Description of Setting}

All testing and training sessions were conducted and completed within the home of a child with autism's caregiver (e.g., parents, grandparents, siblings). Additionally, participants had the availability of consultation with the researcher via phone or email to provide clarification of the training modules content, if needed. No additional information was provided regarding (a) possible answers on the tests of knowledge, or (b) specifics of designing the visual support. It was reasonable to assume that even with Internet-based learning modules, parents would have limited phone contact in order to ask some questions for clarification. However, it was not reasonable to assume that parents would have access to direct, extensive technical assistance, and the provision of such assistance would therefore have become a confounding variable in the study.

\section{Research Design}

The study was a quasi-experimental, non-equivalent control group, pretest-posttest design. The study consisted of a pretest, treatment, and a posttest, and was of the following design:
$\mathrm{O} \times \mathrm{O}$
- - - -
$\mathrm{O} \mathrm{O}$ 


\section{Experimental Controls}

The design controls for credible threats to the internal validity of the study were as follows:

History and maturation. The design controlled for history and maturation (e.g., longitudinal opportunities for learning) by testing treatment and control groups within the same, relatively brief time-frame (i.e., one week).

Testing. This was controlled for by reordering and rewording items that were presented in the posttest (i.e., by creation of an equivalent form) and the existence of the control group that were given the same tests at the same time.

Selection bias. Once selected using a set of predetermined criteria, participants were randomly assigned to treatment and control groups. Additionally, pretest results for both groups were statistically compared to detect the presence or absence of any significant differences. Furthermore, the researcher used descriptive statistics to compare relevant demographic data regarding participants within both groups (see Figure 5 in Appendix A for Parent Demographic Form)

Attrition. I sought to obtain a minimum of 10 participants (e.g., five in control group and five in treatment group) in my study. However, I attempted to recruit 20 participants in case any of the participants decided to drop out or sent in only part of the required material (e.g., pretest but no posttest).

Treatment integrity. Though the online learning of participants was self-directed, participants were required to document their activities using a self-monitoring form. 


\section{Treatment}

The treatment consisted of using material from the Ohio Department of Education Center for Autism and Low Incidence (OCALI) online information website (http://www.ocali.org/) (Smith, 2007). Participants completed free registration using the Autism Internet Modules link located on the OCALI website. Prior to registering, participants completed a pretest consisting of a 10-item quiz that includes multiple-choice, true/false, and sequential order questions (see Figure 6 in Appendix B for the pretest/posttest). Additionally, participants had limited support from the researcher via phone and email to answer any questions they may have had regarding the information provided on the website. (see Figure 7 in Appendix B for the clarification protocol, which is located inside the Parent-Training Booklet).

Once they were logged into the Autism Internet Modules, participants opened the autism at home link. Next, they scrolled down to the visual supports link, and from there they followed the prescribed, self-directed, online training and self-monitored their activity by completing the parent self-monitoring checklist (see Figure 7 in Appendix B for Parent Training Booklet). Included on the checklist were places to check off each completed section of the visual supports link, write down start and stop work times for each section, and record the dates that the sections were started and completed.

\section{Instrumentation}

Parent knowledge. To obtain a measure of parent knowledge of visual strategies the researcher used as the pretest/posttest a 10-item quiz that included multiple-choice, true/false, and sequential order questions (see Figure 6 in Appendix B for Pretest/Posttest). To obtain a measure of treatment integrity, parents self-monitored their completion of each section of the online module (see Figure 7 in Appendix B for Parent Training Booklet). 
Parent application of knowledge. To obtain a measure of parent application of knowledge, the researcher had the participants construct a visual support based on a case study (see Figure 8 in Appendix B for the Case Study For Visual Support Creation). Additionally, the researcher had experts rate these visual supports using a rubric based on the content within the instruction modules. Each quality indicator within the rubric consisted of ratings scored "yes" when the criterion was met, and "no" when the criterion was not met (see Figure 9 in Appendix B for Visual Support Expert Checklist).

Parent Satisfaction. To obtain a measure of social validity/parent satisfaction regarding the treatment, the researcher had the parents complete a survey that was adapted from Ingersoll and Dvortcsak's (2006) Parent Satisfaction Survey (see Figure 10 in Appendix B for the Parent Satisfaction Survey). The adapted survey was a seven item instrument comprising items rated on a of 7-point Likert scale that assessed parental perceptions of statements such as the the clarity of the information presented and the unlimited access to the training.

\section{Data Collection}

Parent knowledge. The researcher sent the participants the pretest by regular mail, and they had 1-week from the time of receipt to complete and return the test (see Figure 6 in Appendix B for Pretest/Posttest and Table 7 in Appendix B for Participant and Researcher Timeline). Within 1 day of sending the pretest, the researcher emailed participants a reminder to complete it. Once the participant completed the pretest, the participant sent the pretest back to the researcher in a prepaid envelope. Participants randomly assigned to the treatment group were sent the parent-training package immediately (see Figure 7 in Appendix B for Parent Training Booklet). Participants had 1 week to complete the training. The participants were also sent the posttest in a sealed envelope with directions to open and complete the posttest upon completion 
of the parent training. Participants had 1 week from the time of completion of the parent training to complete and send back the posttest. Participants randomly assigned to the control group were sent the posttest prior to being provided with the parent training. The participants in the control group were sent the parent training after the researcher received their posttest.

Parent application of knowledge. To obtain a measure of parent application of knowledge, the participants in the treatment group constructed a visual support based on a case study (see Figure 8 in Appendix B for the Case Study for Visual Support Creation). The parents mailed the visual support to the researcher in a prepaid envelope. Parents had 1 week to create and mail the visual support. Prior to implementation of the study, two experts refined a visual support rubric (see Figure 9 in Appendix B for the Visual Support Expert Checklist). Each expert, using the refined rubric, rated each participant created visual support. After the experts rated each visual support, agreement was calculated using Cohen's kappa across the quality indicators.

Parent Satisfaction. To obtain a measure of parent satisfaction the researcher mailed a parent satisfaction survey to the participants who then responded to statements about the training using a 7-point Likert rating scale (see Figure 10 in Appendix B for Parent Satisfaction Survey). Parents completed the form after completion of the pretest, treatment, posttest, and visual support. Additionally, the parent satisfaction survey prompted participants to provide additional feedback to the researcher on each item of the survey by asking them to indicate in writing why they provided each rating. Parents had 1 week from receiving the survey to complete and return the satisfaction form. Comparison of pre- and posttests results from participants in the treatment group and control groups were conducted. The control group was sent the training after receiving their posttest. A measure of treatment integrity was not obtained from the control group 
regarding the training. Nonetheless, parent survey data was collected from the control group to obtain additional participant insight on the parent training.

\section{Data Analysis}

Parent knowledge. The pretest/posttest scores were compared using the Wilcoxon matched pairs signed ranks test. The researcher initially planned to report on the parent selfmonitoring, treatment integrity form by examining and comparing the performance of parents who completed the entire training and the performance of those who did not complete the training yet completed the posttest within the treatment group. However, all of the participants in the treatment group completed the training.

Parent application of knowledge. To obtain a measure of parent application of knowledge, experts independently used the refined rubric to rate each visual support produced by participants in the treatment group. The percentage of agreement between sets of ratings was determined across quality indicators. The percentage of agreement between sets of ratings was determined using Cohen's (1988) kappa statistic that corrects the simple inter-rater agreement for chance agreement, providing a better estimate of agreement than computing a point-by-point agreement that does not correct for chance agreement. The percentage of agreement and the results of each quality indicator were included in the results. It was predetermined that agreement between experts would be deemed "adequate" if it was found to be at or above $80 \%$.

Parent Satisfaction. To obtain a measure of parent satisfaction participants completed a social validity survey. The results were analyzed using the descriptive statistic of mean to show the average rating for each response. 


\section{CHAPTER IV}

Results

\section{Research Questions}

The objective of this chapter is to report the findings of the current study by beginning with a review of the questions. Next, a description of the sample is provided. Last, the results of the data analysis are given to answer each of the research questions. The research questions are as follows:

Main Research Question: What will be the outcomes of using a self-directed, online program to provide training in visual supports to parents of children with autism? Sub-questions:

(a) Does the prescribed use of the training method produce significant gains in parent knowledge of visual supports?

(b) Are parents able to demonstrate an application of their knowledge by creating an appropriate visual support?

(c) What are parental perceptions of using a prescribed, self-directed, online parent-training program?

\section{Description of Sample}

Information confirming that the participants met the inclusionary criteria was collected using a participant demographic form (see Figure 5 in Appendix A for Parent Demographic Form). Nineteen primary caretakers indicated an interest in participating in the study. Three did not meet the inclusionary criteria $(15.8 \%)$; three did not return the preliminary consent forms $(15.8 \%)$, and one participant (5\%) did not complete the study. Of the 19 people who indicated 
interest in participating, 16 people met the inclusionary criteria (82.2\%), and a total of 13 of the 16 entered the study $(81.2 \%)$ by completing and returning the pre-measures (consent form, demographic form, and pretest). Of the 13 participants who entered the study, 12 participants (92.3\%) completed the study (see Table 1 for Table of Recruitment of Participants). The participant that did not complete the training was assigned to the treatment group prior to exiting the study. The participant contacted the researcher after completion of the pre-measures and stated that due to unanticipated work obligations he/she would have to withdraw from the study.

Table 1

Recruitment of Participants

\begin{tabular}{lcc}
\hline Primary caretakers of children ASD & $n$ & Percent \\
\hline $\begin{array}{lc}\text { Indicated interest in participating } \\
\text { Met inclusionary criteria }\end{array}$ & 19 & \\
Returned pre-measures (consent form, demographic & 16 (out of 19) & 82.2 \\
form, and pretest) and were assigned to a group & 13 (out of 16) & 81.2 \\
Completed necessary components of their group & 12 (out of 13) & 92.3 \\
\hline
\end{tabular}

The average age of the participants in both the treatment group and the control group combined was $38.25(S D=8.89)$. The average age of the participants in the treatment group was $36.67(S D=11.45)$, and the average age of the participants in the control group was 39.83 ( $S D=$ 6.08). The average age of the participants' children with ASD in the treatment group was 6.85 years $(S D=4.85)$, and the average age of the participants' children with ASD in the control group was 9.4 years $(S D=9.24)$. The majority of participants were female $(n=11 ; 91.7 \%)$.

Participants learned of the study through several venues. The majority of participants found out about the study through an educational agency (50\%). The remaining participants heard about the study through a support group (16.7\%) and through other venues (16.7\%), such 
as word of mouth. None of the participants learned of the study through the advertisements sent to doctor's offices. The majority of participants identified themselves as Caucasian $(n=10$; 83.3\%), and the only other ethnicity reported was African American $(n=2 ; 16.7 \%)$. The percentage of participants who were married was over $92 \%$ percent. Over $66 \%$ of the participants lived in a town, with the remaining participants living in rural (25\%) and small city $(8.3 \%)$ communities. Many of the participants had a household income of over $\$ 75,000(n=6$; $50 \%)$. Over $16 \%$ percent of the participants were awaiting services. However, all of the participants perceived that they were currently missing or had missed important parent training opportunities on autism because of lack of availability of services. The majority of the participants' relationships to their children with ASD was maternal ( $n=11 ; 91.7 \%)$, in contrast to the fact that the gender of participant's of children with ASD was overwhelmingly male $(n=$ 11; $91.7 \%$ ). Over $91 \%$ of the participant's children received special educational services. Additional services reported were speech therapy $(n=10 ; 83.3 \%)$, occupational therapy $(n=10$; $83.3 \%)$, physical therapy $(n=3 ; 25 \%)$, and "other" $(n=4 ; 33.3 \%)$, e.g., therapeutic services) (see Table 2 for Summary of Participant Age and Table 3 for Summary of Demographic Variables).

Table 2

Summary of Participant Age

\begin{tabular}{|c|c|c|c|c|c|c|}
\hline \multirow[b]{2}{*}{ Demographic Variable } & \multicolumn{3}{|c|}{ Treatment } & \multicolumn{3}{|c|}{ Control } \\
\hline & $n$ & $M$ & $S D$ & $n$ & $M$ & $S D$ \\
\hline Participants ages & 6 & 36.67 & 8.89 & 6 & 39.83 & 6.08 \\
\hline $\begin{array}{l}\text { Ages of children with } \\
\text { ASD }\end{array}$ & 6 & 6.85 & 4.85 & 6 & 9.4 & 9.24 \\
\hline
\end{tabular}


Table 3

Summary of Demographic Variables

\begin{tabular}{|c|c|c|c|}
\hline & Sample Demographics & Treatment & Contro \\
\hline & Percent in both groups & $n$ & $n$ \\
\hline \multicolumn{4}{|l|}{ Gender of Participant } \\
\hline Male & 8.3 & -- & 1 \\
\hline Female & 91.7 & 6 & 5 \\
\hline \multicolumn{4}{|l|}{$\begin{array}{l}\text { How participant heard about } \\
\text { study }\end{array}$} \\
\hline Support group & 16.7 & -- & 2 \\
\hline Educational agency & 50 & 4 & 2 \\
\hline Other & 33.3 & 2 & 2 \\
\hline \multicolumn{4}{|l|}{ Ethnicity } \\
\hline African American & 16.7 & -- & 2 \\
\hline Hispanic & -- & -- & -- \\
\hline Asian American & -- & -- & -- \\
\hline Caucasian & 83.3 & 6 & 4 \\
\hline Other & -- & -- & -- \\
\hline \multicolumn{4}{|l|}{ Marital status } \\
\hline Married & 92.7 & 6 & 5 \\
\hline Divorced & -- & -- & -- \\
\hline Separated & 8.3 & -- & 1 \\
\hline Widowed & -- & -- & -- \\
\hline Single & -- & -- & -- \\
\hline Living with & -- & -- & -- \\
\hline Significant Other & & & \\
\hline \multicolumn{4}{|l|}{ Community type } \\
\hline Rural area & 25 & 1 & 2 \\
\hline Town & 66.7 & 4 & 4 \\
\hline Small city & 8.3 & 1 & -- \\
\hline Metropolitan area & -- & -- & -- \\
\hline \multicolumn{4}{|l|}{ Household income } \\
\hline Less than 20,000 & 8.3 & -- & 1 \\
\hline $20,000-34,999$ & 8.3 & -- & 1 \\
\hline $35,000-49,000$ & 16.7 & 1 & 1 \\
\hline $50,000-74,999$ & 16.7 & 2 & -- \\
\hline Over 75,000 & 50 & 3 & 3 \\
\hline \multicolumn{4}{|l|}{$\begin{array}{l}\text { Participant on waiting list for } \\
\text { services }\end{array}$} \\
\hline Yes & 16.7 & -- & 2 \\
\hline No & 83.3 & 6 & 4 \\
\hline \multicolumn{4}{|l|}{$\begin{array}{l}\text { Perceived difficulty } \\
\text { obtaining services }\end{array}$} \\
\hline Yes & 100 & 6 & 6 \\
\hline
\end{tabular}




\begin{tabular}{|c|c|c|c|}
\hline & \multirow{2}{*}{$\begin{array}{l}\text { Sample Demographics } \\
\text { Percent in both groups }\end{array}$} & \multirow{2}{*}{$\begin{array}{c}\text { Treatment } \\
n\end{array}$} & \multirow{2}{*}{$\begin{array}{c}\text { Control } \\
n\end{array}$} \\
\hline & & & \\
\hline No & -- & -- & -- \\
\hline Gender of children with ASD & & & \\
\hline Male & 91.7 & 6 & 5 \\
\hline Female & 8.3 & -- & 1 \\
\hline $\begin{array}{l}\text { Participants' relationships to } \\
\text { children with ASD }\end{array}$ & & & \\
\hline Mom & 91.7 & 6 & 5 \\
\hline $\mathrm{Dad}$ & 8.3 & -- & 1 \\
\hline Other & -- & -- & -- \\
\hline $\begin{array}{l}\text { Services received by children } \\
\text { with ASD }\end{array}$ & & & \\
\hline Special Education & 91.7 & 6 & 5 \\
\hline Speech therapy & 83.3 & 6 & 4 \\
\hline Occupational therapy & 83.3 & 6 & 4 \\
\hline Physical therapy & 25 & 2 & 1 \\
\hline Other & 33.3 & 2 & 2 \\
\hline
\end{tabular}

\section{Parent Knowledge Results}

To obtain a measure of parent knowledge of visual strategies the researcher used as the pretest/posttest a 10-item quiz that included multiple-choice, true/false, and sequential order questions (see Figure 6 in Appendix B for pretest/posttest). The pretest/posttest scores from the treatment and control groups were compared using the Wilcoxon matched pairs signed ranks test. The researcher also planned to report on the self-monitoring, treatment integrity form by examining and comparing the performance of parents who completed the entire training against those who did not complete the training. However, all participants in the treatment group completed both the parent training and the posttest (see Figure 1 for the Pretest and Posttest Participant Results Graph: Treatment Group and see Figure 2 for the Pretest and Posttest Participant Results Graph: Control Group) 


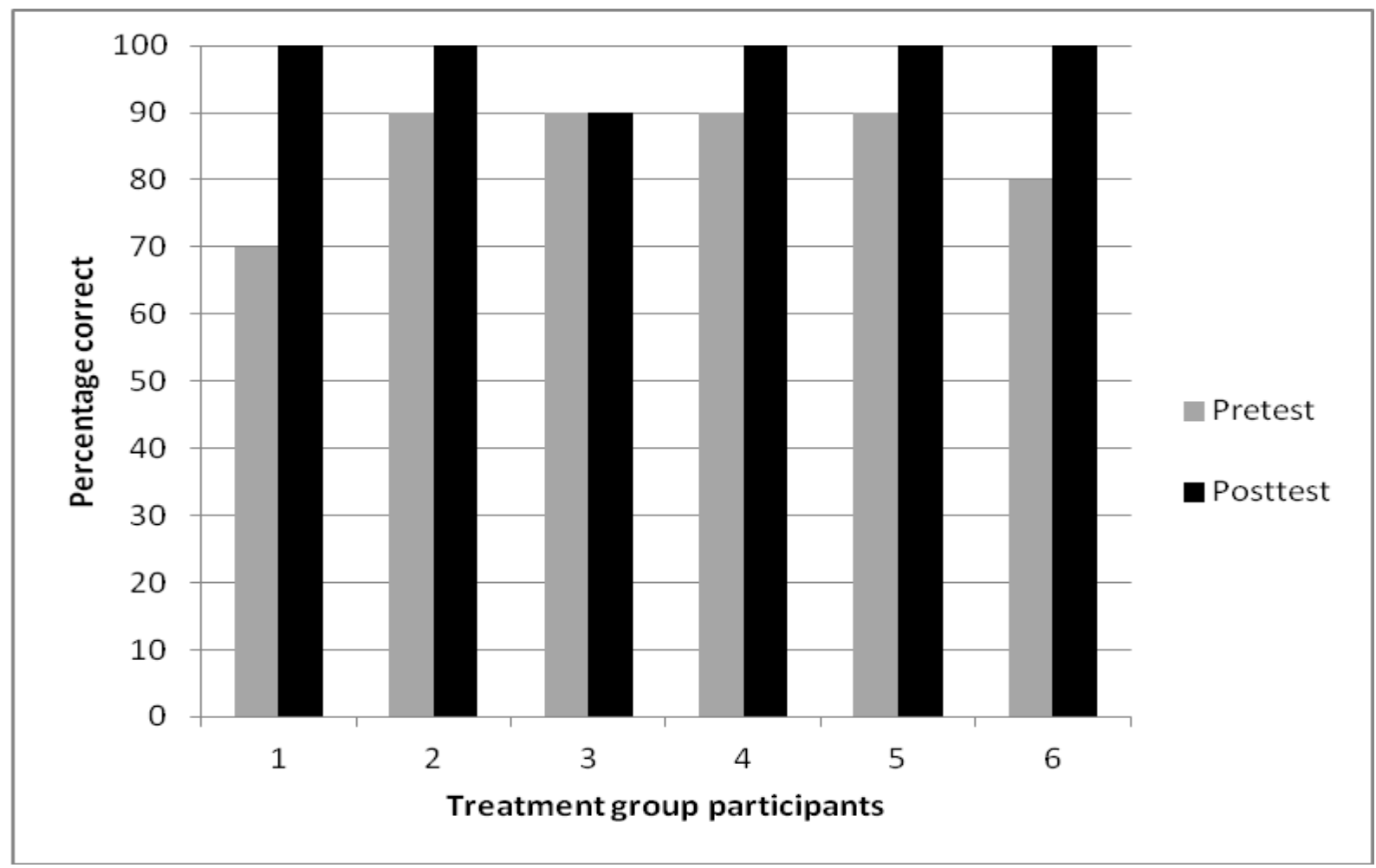

Figure 1. Pretest and Posttest Participant Results Graph: Treatment Group

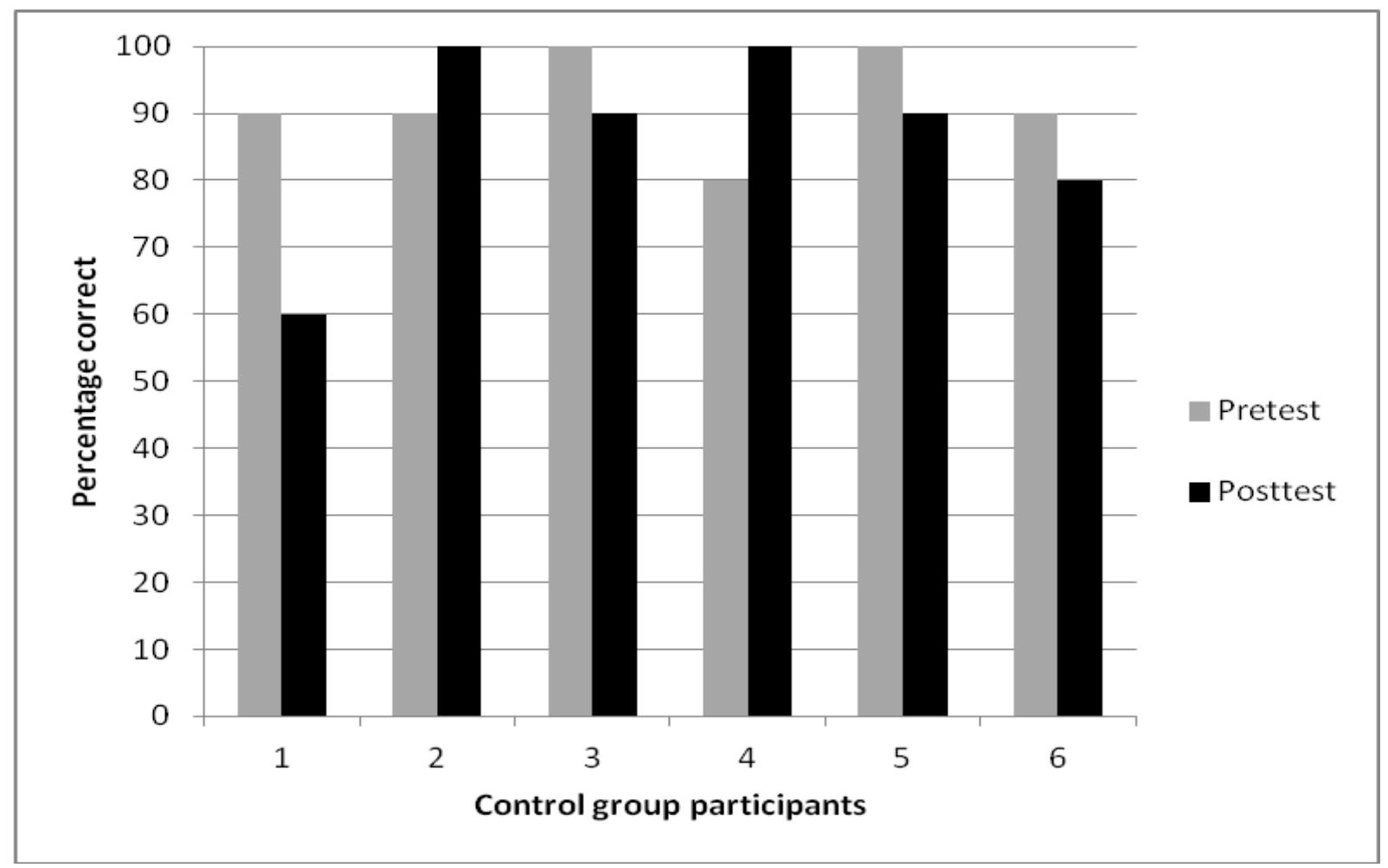

Figure 2. Pretest and Posttest Participant Results Graph: Control Group 
There were a total of 12 participants, six each randomly assigned to treatment and control groups. The results of the treatment group's tests were analyzed if they completed at least $80 \%$ or more of the training. To obtain a measure of treatment integrity, parents self-monitored completion of each section of the online module by using a self-monitoring checklist (see Figure 7 in Appendix B for Parent Training Booklet). All of the participants in the treatment group completed $100 \%$ of the online parent training.

The data were analyzed by using the SPSS version 20.0 software package. Results for both descriptive and inferential statistics are provided. The Wilcoxon matched pairs signed ranks test was applied to compare the pretest and posttest results for the treatment and control groups to determine whether a statistically significant change occurred after training. A $p$-value of .05 or less was considered significant.

Participants in the treatment group spent an average of 2 hours and 1 minute completing the online training module. The amount of time it took participants to complete the online training ranged from 1 hour and 23 minutes to 3 hours and 1 minute $(S D=0.63)$. The average number of days for participants in the treatment group to complete all portions of the study, including from the day the researcher sent the initial consent forms to the day the researcher received the final parent satisfaction survey, was $25.83(M=3.31)$ (see Figure 3 for Treatment Groups Time to Complete Online Module). 


\section{Time in Minutes and Hours to Complete Module}

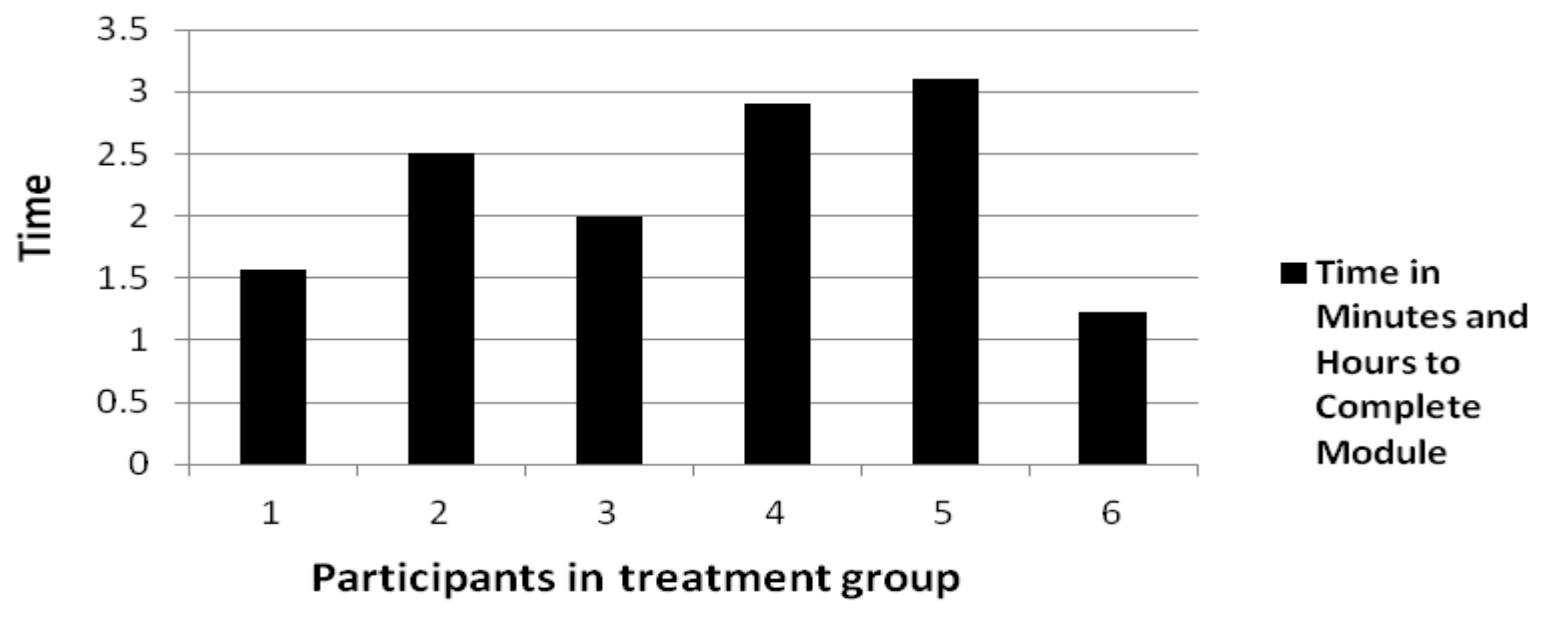

Figure 3. Treatment Groups Time to Complete Online Module

The mean pretest score for participants in the treatment group was 8.5 out of a possible 10 points, with a range of 7-9. The mean pretest score for the control group participants was 9.17, with a minimum score of 8 and a maximum score of 10 . Standard deviations of the scores from both groups were .84 and .75 , respectively. The mean posttest score for participants in the treatment group was $9.83(\min =9 ; \max =10)$, indicating an increase of 1.33 over the pretest mean. The mean posttest score for participant in the control group was $8.67(\min =6 ; \max =10)$, indicating a decrease of 0.50 below the pretest mean.

The results of the Wilcoxon signed rank test indicated a significant difference $(z=-2.06$, $p=.039$ ) between the pretest and posttest results for the treatment group. The results for the control group showed no significant difference between their pre and post scores $(z=-.65, p=$ $.52)$. Overall, $83 \%$ of the treatment group $(n=5)$ scored higher on the posttest than the pretest, with only $17 \%$ scoring the same and no one scoring lower. Only $33 \%$ of the participants in the control group scored higher on the posttest than the pretest, with $67 \%$ scoring lower. 


\section{Parent Application of Knowledge Results}

To obtain a measure of parent application of knowledge, participants in the treatment group constructed a visual support based on a case study (see Figure 8 in Appendix B for the Case Study for Visual Support Creation). The visual support was then compared to a rubric that was written by the researcher and then revised/refined by two experts in ASD (see Figure 9 in Appendix B for the Visual Support Expert Checklist). This rubric was specifically created to evaluate the provided case study only and not intended for use with all other visual supports. The two experts and the researcher then used the rubric to rate each visual support. The percentage of agreement between sets of ratings was calculated using Cohen's (1988) kappa.

Interrater agreement between the two expert raters was calculated at 80\% $(\mathrm{kappa}=.80$; $p<.001$ ), indicating a "very good" level of agreement (Altman, 1991). Interrater agreement between expert one and the researcher was calculated at 77\% (kappa $=.77 ; p<.001)$, indicating a "good" level of agreement (Altman, 1991). Last, interrater agreement between expert two and the researcher was also calculated at 77\% (kappa $=.77 ; p<.001)$. After determining there was a good level of agreement between the researcher and the experts and a high level of agreement between the two experts, the researcher proceeded to report the three reviewer's findings.

Each participant in the treatment group created a visual support that was compared to the revised rubric and determined to be either satisfactory or unsatisfactory. This determination was based on meeting the criteria for each of the three main items on the rubric. The criteria to pass as satisfactory included the incorporation of needed pictorial representations, inclusion of information enabling the child to understand his surroundings, and articulating why it was helpful for the child in the case study to have information presented in the form of a visual support. Additionally, the reviewers reported on additional evaluative information (e.g., the 
participant adding information beyond what was requested by the researcher) and, when needed, the reviewers provided additional summative comments, for example, providing information that a visual support was satisfactory even though it did not pass one of the three items on the rubric. Subsequently, the reviewers would then state why it was satisfactory (e.g., the participants provided additional information that was an example of positive practices for children with autism) (see Table 4 for the Summary of Visual Support Rubric).

Table 4.

Summary of Visual Support Rubric

\begin{tabular}{|c|c|}
\hline Main Item Number & Sub-category \\
\hline $\begin{array}{l}\text { 1. The participant's visual } \\
\text { support includes } 3 \text { or more } \\
\text { of the following pictorial } \\
\text { representations: }\end{array}$ & $\begin{array}{l}\text { (a) A pictorial representation of Jack and/or, (b)a pictorial } \\
\text { representation of Andrew and/or, (c)a pictorial } \\
\text { representation of a vehicle or van and/or, (d)a pictorial } \\
\text { representation of school or preschool. }\end{array}$ \\
\hline $\begin{array}{l}\text { 2. The participant created a } \\
\text { visual support that } \\
\text { includes information the } \\
\text { child needed to know or } \\
\text { understand by including } 2 \\
\text { or more of the following } \\
\text { pieces of information: }\end{array}$ & $\begin{array}{l}\text { (a) Information on what activity is taking place now: } \\
\text { Andrew is riding in the van and/or, (b) information on what } \\
\text { activity is will take place next: Andrew will be going to } \\
\text { school and/or, (c) includes that a change will occur in the } \\
\text { regular schedule: On Tuesdays and Thursdays Jack will be } \\
\text { picked up and ride to school in the van with Andrew. }\end{array}$ \\
\hline $\begin{array}{l}\text { 3. The participant was able } \\
\text { to articulate why it would } \\
\text { help Andrew to have the } \\
\text { information presented in } \\
\text { the form of a visual } \\
\text { support by the inclusion of } \\
2 \text { or more of the } \\
\text { following: }\end{array}$ & $\begin{array}{l}\text { (a) A statement that the visual support helps Andrew know } \\
\text { what activity will occur, and/or, (b) a statement that the } \\
\text { visual support helps Andrew know that a change will occur } \\
\text { in the regular schedule, and/or, (c) a statement that the } \\
\text { visual support might help reduce Andrew's frustration } \\
\text { and/or anxiety, and/or, (d) a statement that Andrew relies on } \\
\text { the use of a visual support for other transitional activities } \\
\text { (e.g., morning routine). }\end{array}$ \\
\hline
\end{tabular}

Based on the feedback from the three reviewers (two experts and the researcher) the results for each participant on each item are provided. Additionally, the overall rating (satisfactory or unsatisfactory) of each participant's visual support based on the reviewers ratings and summative comments are included (see Table 5 for the Summary of Reviewers Overall 
Visual Support Ratings). Reviewer 1 rated satisfactory the three main items for participants 2, 4, and 5. This reviewer's overall rating for each participant's visual support was also satisfactory. Reviewer 1 rated items 1 and 2 satisfactory and item 3 unsatisfactory for participant number 6. However, the reviewer further stated in the summative comments that even though participant 6 received a satisfactory in 2 out of the 3 main items and "did not accomplish the task in the same way as the other participants," the visual support the participant created would "conceivably work." The researcher, based on the summative comments of the reviewer, recorded an overall satisfactory rating for this participant. For participant 1, reviewer 1 rated items 1 and 3 satisfactory and item 2 unsatisfactory. The overall visual support rating for participant 1 was unsatisfactory. The reviewer further noted that the product did not "clearly indicate an ordered progression of events." Last, reviewer 1 found items 2 and 3 satisfactory for participant number 3. However, item 1 was found unsatisfactory, leaving participant 3 with an overall unsatisfactory rating on this visual support.

Reviewer 2 found the three main items for participants 1,2,4,5, and 6 satisfactory. The overall rating for each participant's visual support was also satisfactory. The reviewer further noted that although participant 1 created a "very basic" visual support, the reviewer thought that it "got the intent of the support." As with reviewer 1, reviewer 2 noted that participant 6 had an "interesting way to present" the visual information. The reviewer further noted the participant's mention of the use of a photograph for a visual support, as opposed to pictorial representations of real life (e.g., people and/or places) as an example of a positive practice for children with ASD. The reviewer found only item 3 satisfactory for participant number 3 , leaving the visual support with an overall unsatisfactory rating. 
Reviewer 3, the researcher, rated as satisfactory the 3 main items for participants 2, 4, 5, and 6. This reviewer's overall rating for each of these participants was also satisfactory. Reviewer 3 was in agreement with reviewers 1 and 2 in that the overall rating of participant 3 was unsatisfactory. However, reviewer 3 agreed with reviewer 1 in that participant 1 created a visual support that did not meet the criteria to be rated satisfactory. Reviewer 3 stated, "Too much information was missing" to be used as an effective visual support.

In summary, using the revised rubric, the 3 reviewers were in agreement that participants $2,4,5$, and 6 created a visual support that was satisfactory, based on the information the participants were provided within the case study. The reviewers were also in agreement that participant number 3 did not create a satisfactory visual support. However, the reviewers had mixed ratings on the visual support of participant number 1, with reviewer 1 and 3 rating the support as unsatisfactory and reviewer 2 rating the support as satisfactory.

Table 5

Summary of Reviewers' Overall Visual Support Ratings

\begin{tabular}{lccc}
\hline Participant & Reviewer 1: Visual & Reviewer 2: Visual & Reviewer 3: Visual \\
Number & Support Rating & Support Rating & Support Rating \\
\hline 1 & Unsatisfactory & Satisfactory & Unsatisfactory \\
2 & Satisfactory & Satisfactory & Satisfactory \\
3 & Unsatisfactory & Unsatisfactory & Unsatisfactory \\
4 & Satisfactory & Satisfactory & Satisfactory \\
5 & Satisfactory & Satisfactory & Satisfactory \\
6 & Satisfactory & Satisfactory & Satisfactory \\
\hline
\end{tabular}

\section{Parent Satisfaction Results}

To obtain parental perceptions of using a prescribed, self-directed, online parent-training program, a measure of satisfaction regarding the treatment was attained. The researcher asked the parents in the treatment group to complete a survey after they had completed the parent training. Pretest and posttest results comprised all of the information needed from the control 
group. However, the control group was provided with the training at the end of the study. A measure of treatment integrity was not obtained from the control group regarding the training. Nonetheless, parent survey data were collected from the control group to obtain additional social validity data on the training. The participants in both groups responded to statements about the training using a 7-point Likert rating scale. Participants were asked to respond to 7 statements and to rate each statement, with 1 indicating that they strongly disagreed with the statement and 7 indicating that they strongly agreed with the statement. The survey was adapted from Ingersoll and Dvortcsak's (2006) Parent Satisfaction Survey (see Figure 10 in Appendix B for the Parent Satisfaction Survey). Additionally, the parent satisfaction survey prompted participants to provide additional feedback to the researcher on each item by asking them to indicate in writing why they provided the given rating. All of the participants in the treatment group responded to the parent survey, but only five out of the six participants in the control group responded (83.3\%). The results were analyzed using the descriptive statistic of mean to show the average rating for each response (see Table 6 for the Parent Survey Response).

Table 6

Parent Survey Response

\begin{tabular}{|c|c|c|c|c|}
\hline \multirow[b]{2}{*}{ Statement (rating on 7-point Likert scale) } & \multicolumn{2}{|c|}{$\begin{array}{c}\text { Treatment } \\
(n=6)\end{array}$} & \multicolumn{2}{|c|}{$\begin{array}{l}\text { Control } \\
(n=5)\end{array}$} \\
\hline & $M$ & $S D$ & $M$ & $S D$ \\
\hline $\begin{array}{l}\text { 1. The online training modules were clear } \\
\text { and understandable }\end{array}$ & 6.83 & 0.41 & 6.8 & 0.45 \\
\hline $\begin{array}{l}\text { 2. The format of the program was } \\
\text { appropriate (self-directed, online } \\
\text { training) }\end{array}$ & 6.67 & 0.52 & 6.8 & 0.45 \\
\hline $\begin{array}{l}\text { 3. The unlimited access to the online } \\
\text { training was convenient. }\end{array}$ & 6.83 & 0.41 & 6.8 & 0.45 \\
\hline $\begin{array}{l}\text { 4. I feel that I gained knowledge of visual } \\
\text { supports. }\end{array}$ & 6.5 & 0.84 & 6.8 & 0.45 \\
\hline
\end{tabular}




\begin{tabular}{|c|c|c|c|c|}
\hline \multirow[b]{2}{*}{ Statement (rating on 7-point Likert scale) } & \multicolumn{2}{|c|}{$\begin{array}{c}\text { Treatment } \\
(n=6)\end{array}$} & \multicolumn{2}{|c|}{$\begin{array}{l}\text { Control } \\
(n=5)\end{array}$} \\
\hline & $M$ & $S D$ & $M$ & $S D$ \\
\hline $\begin{array}{l}\text { 5. I feel this is a good way to learn } \\
\text { information to help me meet my child's } \\
\text { needs. }\end{array}$ & 6.67 & 0.82 & 6.4 & 1.34 \\
\hline $\begin{array}{l}\text { 6. The online training modules were easy } \\
\text { to use. }\end{array}$ & 6.67 & 0.52 & 6.8 & 0.45 \\
\hline 7. I enjoyed this online training program. & 6.33 & 1.21 & 6.8 & 0.45 \\
\hline
\end{tabular}

The parent ratings in both groups were overwhelmingly positive, and the participant feedback provided additional insight as to why parents provided the ratings. For statement 1 , ("The online training modules were clear and understandable."), both the treatment group $(M=$ 6.83, $S D=0.41)$ and the control group $(M=6.8, S D=0.45)$ responded positively. One participant in the treatment group wrote, "The online trainings and modules are understandable and clear, while making it easy to educate one's self on numerous topics." Further support for the modules was provided by participant feedback from the control group. One participant wrote, "I had no trouble with the training [and] enjoyed the videos."

Statement 2 (“The format of the program was appropriate.”) received positive feedback from both groups as well. The treatment group $(M=6.67, S D=0.52)$ and the control group $(M=$ $6.8, S D=0.45)$ provided positive supporting statements. For example, a participant in the treatment group wrote that the modules were "easy to navigate." Participant written feedback in the control group was also positive. For example, one participant stated that the trainings were "very clear and easy to understand."

Based on responses to statement 3, participants in both groups, treatment $(M=6.83, S D=$ $0.41)$ and control $(M=6.8, S D=0.45)$, thought that the unlimited access to the online training 
was convenient. A treatment group participant wrote that the "unlimited access to these trainings makes it very convenient for a busy schedule." Further evidence of the perceived convenience of the online training was provided by another treatment group participant who conveyed, "Our schedules are very hectic [and] it was great to be able to complete [the training] on my own time." One member of the control group provided additional insight with the statement, "I was able to access [the] training when it was convenient to me, which was 3:00 a. m. in the morning." Another member of the control group wrote, "I had to log on multiple times due to interruptions at home. That was very convenient because I was able to complete this [online training] when I had time."

For statement 4 , participants in the treatment group $(M=6.5, S D=0.84)$ and the control group $(M=6.8, S D=0.45)$ thought that they gained sufficient knowledge of visual supports. "The visual support module did a great job of not only describing the life changing benefits, but also providing detailed examples of a variety of different systems," a participant in the treatment group wrote. A participant in the control group added to his high numerical rating by stating that he "definitely learned new things."

The feedback for statement 5, ("I feel this is a good way to learn information to help me meet my child's needs."), was also met with high marks. Participants in both the treatment group $(M=$ $6.7, S D=0.82)$ and the control group $(M=6.4, S D=1.34)$ also provided corresponding remarks. "I feel strongly that the information provided to me will aid in the improvement of my needs," wrote a member of the treatment group. Additional written support came from a participant in the control group who stated that she will "use the site in the future."

The participants in both the treatment $(M=6.76, S D=0.52)$ and the control $(M=6.8, S D=$ 0.45) groups thought that the online training modules were easy to use. Furthermore, the 
participants in both groups provided support for the high marks for statement 6 . A participant in the treatment group added, "There was a lot of reading on some section[s] but the system was very easy overall." A member of the control group communicated that the module was "very easy to follow."

The treatment group $(M=6.33, S D=1.21)$ and the control group $(M=6.8, S D=0.45)$ both perceived benefit from this online training program. Support for the modules was provided by treatment group participants' written feedback. For example, one of the participants wrote, "This online program will help me and my family in a variety of different ways." Yet another within this group communicated that the training "gave me new ideas for my [child, and] I learned why some schedules are used and how they help." Participants in the control group provided similar positive statements, such as, "It was very informative to me [and] it is also the way they teach my [child] in preschool so I enjoyed learning about how they are teaching [my child]." Additional supportive statements from the control group included, "I hope I find more training like this," and, "I learned something new."

\section{Results Summary}

Overall, 12 participants, six in the treatment and six in the control group, completed the study. The pretest/posttest scores were analyzed, and the results demonstrated that parents could obtain significant levels of knowledge of a research-based support by using online training modules. A majority of the participants were also were able to apply that knowledge to the creation of a visual support that met important quality standards, as rated by a series of experts. Last, parents' overall perceptions of the training were positive in terms of both numerical scores and written statements. 


\section{CHAPTER V}

\section{Summary and Conclusions}

\section{Summary}

The purpose of the current study was to demonstrate that parents who have children diagnosed with autism could obtain and apply knowledge of a research-based support for their children by utilizing a prescribed, self-directed, online program, giving families another possible method of obtaining training to help meet the discrepancy that exists between need and service. The main research question of the study was to find the functional outcome of using a selfdirected, online program to provide training in visual supports to parents of children with autism. Using a quasi-experimental, non-equivalent control group, pretest-posttest design to test knowledge obtained from treatment, the findings indicate that parents can both obtain and apply adequate knowledge of a research-based support. Furthermore, the findings show that parents' perceptions of utilizing this method of training are positive.

The results show that over $92 \%(\mathrm{n}=12)$ of the participants who entered the study completed it. The first sub-question sought to to discover if the use of the training method could produce significant gains in parent knowledge of visual supports. Analysis of the results shows that parents in the treatment group scored significantly higher on the posttest, as opposed to the control group's test results that showed a decreased mean score on the posttest and no significant difference between pretest and posttest scores. Pretest scores were relatively high for participants in the treatment group (five out of six scored $80 \%$ or above), which was likely to be a function of correct guessing on items such as multiple choice and true/ false. This resulted in a ceiling effect that limited room for improvement on the posttest. Although scores for the majority of participants improved from pre to post (except for one, which had identical pre/post scores), 
most of the improvement assessed by statistical analysis seemed to be attributable to participants 1 and 6. However, the consistent pattern of improvement in the experimental group was in stark contrast to the highly variable pre/post performance of the control group, suggesting that the application of the treatment resulted in more stable, consistent performance among participants. This is a highly desirable outcome in any training study. This demonstrates that parents can obtain adequate knowledge of visual supports utilizing a self-directed, online program, as seen in other related fields (Hudson, et al., 2003; Richards \& Alvarenga, 2002). These findings are in line with findings from other studies (e.g., Ingersoll \& Dvortcsak, 2006; Nefdt et al., 2010) that show parents can make significant, positive gains in knowledge of interventions for their children. Moreover, as in Nefdt et al. (2010), this study demonstrates that parents can obtain at least a preliminary working knowledge of an intervention in a relatively brief amount of time (i.e., 1-week).

The second sub-question dealt with obtaining information on parents' ability to apply their knowledge by creating an appropriate visual support based on a case study. The results are based on the feedback of two experts and the researcher who measured the parent-created visual supports against a revised visual support rubric. This rubric was specifically created to evaluate the provided case study only, and is not intended for use with all other visual supports, although it could be further adapted to meet the evaluative needs of others utilizing visual supports. An analysis of the results reveals that the majority of parents who received training using this method of delivery can in turn correctly apply the knowledge. However, the discrepancy in ratings for participant 1 among the three reviewers suggests that the creation and subsequent application of a visual support is somewhat subjective and in need of direct application to the individual with ASD in order to be fully and validly evaluated. In summation, this fact should be 
placed within the context to the fact that overall agreement across visual support ratings for all participants was adequately high, an important finding within the current study. Another important fact is that three of the participants who received overall satisfactory ratings by all three reviewers were the participants who spent the greatest amount of time on the parent training. Similar to the findings of Solomon, et al. (2007), this suggests that the more time a participant spends independently learning an intervention, the better the participant's knowledge of the intervention tends to be. Two of the participants who spent the least amount of time on the training received unsatisfactory ratings for their visual support, and this further supports the correlation between times spent independently learning an intervention and increased participant knowledge of the intervention.

The third sub-question sought parental perceptions of using a prescribed, self-directed, online parent-training program. Analysis of the numerical survey responses indicated that participants in both groups were very satisfied with important aspects and outcomes of the training that were also supported by the written feedback on the survey. Parents reported that they liked the accessibility of the training and that it was easy to use. The results of the written feedback were consistent with the findings of Lucyshyn et al. (2007) and Parette, et al. (2010), who found that families like flexibility in training schedule to be able to work at their own pace and want to have more web-based informational supports available. For example, one parent in this study wrote that she would like to "find more training like this," and many of the parents appreciated the ability to complete study at their "own pace" with "access when it was convenient." Yet another participant in the study wrote, "I had to log on multiple times due to interruptions at home. That was very convenient because I was able to complete this (online training) when I had time.” However, it should be noted that, for some parents, the independent 
format may not be completely adequate without the addition of other supports, for as one participant in the control group wrote, "I don't know that some people will have that much time to do the training."

\section{Conclusions}

There is a continuing discrepancy between need and available services for children with ASD and their families (Carbone, et al., 2010; Kalkbrenner et al., 2011; Montes et al., 2009). Many families face barriers because of their geographic location (Applequist, 2009, Mandell et al., 2005) or because of a delay of services (Carbone et al., 2010). The results of the study provide support for the utilization of online training for parents of children with ASD. The use of videos (Elder et al, 2003; Kashinath et al., 2006) and manuals (Nefdt et al., 2010) for parent training have steadily been incorporated within parent training programs to provide additional layers of informational support. The use of online training can be added as another layer of support to meet parental informational needs.

Online parent training may also provide practitioners and service providers with an alternative method that can be used to reach geographically isolated families, better meet their need for knowledge, and provide an alternative, customized plan of training that better fits individual needs and lifestyles. Moreover, this method of training could be cost and time efficient for professionals by reducing travel expenses and providing a method of training that better accommodates their scheduling needs. By using this method to reach families, professionals may be able to begin to close the gap that exists within the availability of services provided to families. Additionally, by giving parents increased access to interventions delivered by methods such as those described within the current study, parents may learn strategies that could give them the ability to act as their children's direct service provider and empower them to 
proactively address some of their children's intervention needs. This could be especially beneficial to families facing a discrepancy between need and service.

The results of this study support the use of Internet-based, self-directed instruction to provide families with intervention training, as consistent with the previous research efforts of Nefdt et al. (2010). Furthermore, the results are consistent with findings based on the works of researchers in related fields, whose efforts show support for the use of self-directed, web-based training within the home setting (Carpenter et al., 2004; Pacifici et al., 2006; Richards \& Alvarenga, 2002; Sanders et al., 2008). The results of this study combined with the results of previous research studies in this field and related fields add to growing body of support for the use of this type of training. This information may be useful to professionals who are facing the growing numbers of families who have children diagnosed with autism (Centers for Disease Control and Prevention, 2012), for this increase in numbers will surely come with an increased need for available services to meet these children's unique and varied social, communicative, and behavioral challenges. Additionally, this study may be of value to related fields as a possible way to provide families with knowledge of their children's disabilities or illnesses.

\section{Limitations}

The study had a number of limitations. First, purposeful sampling enabled the researcher to identify participants with the most relevant characteristics for study. The inability to use stratified sampling methodology makes generalization of the results difficult. Second, due to the use of self-selection in some of the avenues within which the study was advertised (e. g., a parent support group), parents who chose to participate in the study may have been more inherently motivated to complete it, which could have skewed results in a positive direction that is not typical for the population. Third, while rural areas have experienced rapid broadband growth 
since 2000 (Stenberg \& Low, 2009), the availability of these services has not yet become consistent across all areas of the United States.

\section{Recommendations for Future Research}

An analysis of the data obtained by this study reveals recommendations for future research studies. Presently, the researcher recommends expanding both the duration of the current study and the questions that it explores. The training provided preliminary information on the knowledge acquisition and self-directed creation of visual supports but was not comprehensive in terms of developing parents' implementation of this type of support with their children and monitoring and assessing effects on behavior, to develop deep knowledge needed to encompass the complex needs of a child with autism. Moreover, the use of visual supports has been established as an effective, evidence-based practice for children with autism (National Autism Center, 2009; Rogers \& Vismara, 2008). As seen in the mixed ratings of the first participant's visual support, the creation of visual supports and subsequent ratings of such a creation can involve subjectivity. In the end, the ultimate judgment of whether or not a visual support is effective can only be measured by actually using it with a child and taking data on the intended behavioral change. Research demonstrates that parents, when instructed on evidencebased interventions, can successfully apply the knowledge to their children's individual needs (Anan et al., 2008; Koegel et al., 2002; Symon, 2005). Furthermore, other related fields have used online instruction to expand parents' knowledge of their children's disabilities (Pacifici et al., 2006; Carpenter et al., 2004). However, there is a dearth of research in the field of autism investigating parent's application of knowledge of evidence-based interventions that they obtain from online instruction and apply to help their own children with ASD. Future research should focus on providing parents with prescribed, self-directed training that directly applies the 
knowledge to their children (e.g., by creating a visual support based on their own child's needs) and then tracks data on its usage. In addition, future studies should seek to expand the duration and scope of the present study to include implementation and follow-up phases within which parents use their acquired knowledge and skill with their children. Ideally, this type of study would include (a) more comprehensive measures of treatment integrity regarding parent learning and implementation of the intervention, and (b) a multiple baseline across participants (children with ASD) that measures change in the rate of a relevant dependent variable allowing the demonstration of a possible functional relation between the training and positive outcomes.

Moreover, though the use of visual supports has been established as an effective, evidence-based practice for children with ASD (National Autism Center, 2009; Rogers \& Vismara, 2008), the varied and complex needs of individual children with ASD require those who work with and care for these children to be knowledgeable in a wide variety of interventions and supports. Future research should therefore look at expanding the types of training opportunities offered in order to evaluate the ability of parents to gain knowledge in a wider range of interventions with varying levels of complexity.

Last, the majority of participants within the current study were married, Caucasian, and had household incomes over $\$ 75,000$ per year. Future research should be conducted that includes parents from a larger range of both socioeconomic and ethnic backgrounds. This would help ascertain if there are any differences across these variables in parents' ability to effectively and consistently access and use online training (e.g., variance in level of access to a computer and the Internet). Another relevant avenue of exploration (as noted by one participant, i.e., "I don't know that some people will have that much time to do the training,") deals with the provision of parental supports for using this method of training at home. For example, 
researchers should examine the differences between participants who are married or share parenting responsibilities with a significant other versus those who are single parents to determine if there are any differences between the two groups (e.g., in the ability to successfully complete and implement the training).

Overall, the results of the current study suggest that using a self-directed, online program to provide training to parents may serve to give families another possible method of obtaining skills that have the potential to positively impact the lives of their children with ASD. Using this method of parental instruction may help fill a portion of the gap created by the need for services and the lack of availability of services. Additionally, interventions based on the current study could give parents the ability to act as a direct service provider in order to fulfill a part of their children's specialized behavioral and education needs. 


\section{REFERENCES}

Altman, D. G. (1991). Practical statistics for medical research. London England: Chapman Hall. American Psychiatric Association. (2000). (4 ${ }^{\text {th }}$ ed.). Diagnostic and statistical manual of mental disorders. Washington, DC: Author.

Anan, R. M., Warner, L. J., McGillivary, J. E., Chong, I. M., \& Hines, S. J. (2008). Group intensive family training (GIFT) for preschoolers with autism spectrum disorders. Behavioral Interventions, 23, 165-180. doi:10.1002/bin.262

Applequist, K. (2009). Parent perspectives of special education: Framing of experiences for prospective special educators. Rural Special Education Quarterly, 28(2), 3-16.

Billingsley, B., Israel, M., \& Smith, S. (2011). Supporting new special education teachers. Teaching Exceptional Children, 43, 20-29.

Brookman-Frazee, L. (2004). Using parent/clinician partnerships in parent education programs for children with autism. Journal of Positive Behavior Interventions, 6, 195-213.

Carbone, P. S., Behl, D. D., Azor, V., \& Murphy, N. A. (2010). The medical home for children with autism spectrum disorders: Parent and pediatrician perspectives. Journal of Autism \& Developmental Disorders, 40, 317-324. doi: 10.1007/s10803-009-0874-5

Carpenter, E. M., Frankel, F., Marina, M., Naihua, D., \& Smalley, S. L.(2004). Internet treatment delivery of parent-adolescent conflict training for families with an ADHD teen: A feasiblity study.Child \& Family Behavior Therapy, 26(3), 1-19.

Centers for Disease Control and Prevention (CDC). (2012). Prevalence of autism spectrum disorders. Autism and Developmental Disabilities Monitoring Network, United States, 2012, 61(SS03). 1-19. 
Coe, J. R., \& Youn, E. (2008). Past, present, and future trends in teaching clinical skills through web-based learning environments. Journal of Social Work Education, 44, 95-115.

Cohen, J. (1988). Statistical power analysis for the behavioral sciences ( $2^{\text {nd }}$ ed.). Mahwah, NJ: Erlbaum.

Coolican, J., Smith, I. M., \& Bryson, S. E. (2010). Brief parent training in pivotal response treatment for preschoolers with autism parent training in PRT. Journal of Child Psychology \& Psychiatry, 51, 1321-1330. doi: 10.1111/j.1469-7610.2010.02326.x

Connell, S., Sanders, M. R., \& Markie-Dadds, C. (1997). Self-directed behavioral family intervention for parents of oppositional children in rural and remote areas. Behavior Modification, 21(4), 379.

Dillenburger, K., Keenan, M., Doherty, A., Byrne, T., \& Gallagher, S. (2010). Living with children diagnosed with autistic spectrum disorder: Parental and professional views. British Journal of Special Education, 37, 13-23. doi: 10.1111/j.1467-8578.2010.00455.x

Dillenburger, K., Keenan, M., Gallagher, S., \& McElhinney, M. (2004). Parent education and home-based behaviour analytic intervention: An examination of parents' perceptions of outcome. Journal of Intellectual \& Developmental Disability, 29, 119-130.

Dymond, S., Gilson, C., \& Myran, S. (2007). Services for children with autism spectrum disorders. Journal of Disability Policy Studies, 18, 133-147.

Elder, J. H., Valcante, G., Won, D., \& Zylis, R. (2003). Effects of in-home training for culturally diverse fathers of children with autism. Issues in Mental Health Nursing, 24, 273-295. 
Gibson, J. L., Pennington, R. C., Stenhoff, D. M. \& Hopper, J. S. (2010). Using desktop videoconferencing to deliver interventions to a preschool student with autism. Topics in Early Childhood Special Education, 29, 214-225.

Gray, C. (1994a). The new social story book. Arlington, VA: Future Horizon

Gray, C. (1994b). Comic strip conversations. Arlington, VA: Future Horizon

Hartley, S. L., Barker, E. T., Seltzer, M. M., Greenberg, J., Bolt, D., Floyd, F., \& Orsmond, G. (2010). The relative risk and timing of divorce in families of children with an autism spectrum disorder. Journal of Family Psychology, 24, 449-457. doi: 10.1037/a0019847

Hudson, A. M., Matthews, J. M., Gavidia-Payne, S. T., Cameron, C. A., Mildon, R. L., Radler, G. A., Nankervis, K. L. (2003). Evaluation of an intervention system for parents of children with intellectual disability and challenging behaviour. Journal of Intellectual Disability Research, 47(4/5), 238-249. doi:10.1046/j.1365-2788.2003.00486.x

Hume, K., Bellini, S., \& Pratt, C. (2005). The usage and perceived outcomes of early intervention and early childhood programs for young children with autism spectrum disorder. Topics in Early Childhood Special Education, 25, 195-207.

Ingersoll, B., \& Dvortcsak, A. (2006). Including parent training in the early childhood special education curriculum for children with autism spectrum disorders. Journal of Positive Behavior Interventions, 8, 79-87. 
Kalkbrenner, A. E., Daniels, J. L., Emch, M., Morrissey, J., Poole, C., \& Chen, J.-C. (2011). Geographic access to health services and diagnosis with an autism spectrum disorder. Annals of Epidemiology, 21, 304-310. doi: 10.1016/j.annepidem.2010.11.010

Kashinath, S., Woods, J., \& Goldstein, H. (2006). Enhancing generalized teaching strategy use in daily routines by parents of children with autism. Journal of Speech, Language \& Hearing Research, 49, 466-485. doi:10.1044/1092-4388(2006/036)

Koegel, R., Symon, J., \& Koegel, L. (2002). Parent education for families of children with autism living in geographically distant areas. Journal of Positive Behavior Interventions, 4, 88-103.

Koegel, R. L., \& Koegel, K. K. (2006). Pivotal response treatments for autism: Communication, social \& academic development. Baltimore, MD: Brookes Publishing.

Kohler, F. W. (1999). Examining the services received by young children with autism and their families: a survey of parent responses. Focus on Autism \& Other Developmental Disabilities, 14(3), 150.

Kuhaneck, H. M., Burroughs, T., Wright, J., Lemanczyk, T., \& Darragh, A. R. (2010). A qualitative study of coping in mothers of children with an autism spectrum disorder. Physical \& Occupational Therapy in Pediatrics, 30, 340-350. doi: $10.3109 / 01942638.2010 .481662$

Laugeson, E., Frankel, F., Mogil, C., \& Dillon, A. (2009). Parent-assisted social skills training to improve friendships in teens with autism spectrum disorders. Journal of Autism \& Developmental Disorders, 39, 596-606. doi:10.1007/s10803-008-0664-5 
Lecavalier, L., Leone, S., \& Wiltz, J. (2006). The impact of behaviour problems on caregiver stress in young people with autism spectrum disorders. Journal of Intellectual Disability Research, 50, 172-183. doi: 10.1111/j.1365-2788.2005.00732.x

Lucyshyn, J. M., Albin, R. W., Horner, R. H., Mann, J. C., Mann, J. A., \& Wadsworth, G. (2007). Family implementation of positive behavior support for a child with autism. Journal of Positive Behavior Interventions, 9, 131-150.

Ludlow, B, Galyon-Keramidas, C. \& Landers E. J. (2007). "Project STARS: Using desktop conferencing to prepare autism specialists at a distance." Rural Special Education Quarterly, 26(4), 27-35.

Mahoney, G., Boyce, G., Fewell, R., Spiker, D., \& Wheeden, C. (1998). The relationship of parent-child interaction to the effectiveness of early intervention services. Topics in Early Childhood Special Education, 18, 5-17.

Mandel, U., Bigelow, K. M., \& Lutzker, J. R. (1998). Using video to reduce home safety hazards with parents reported for child abuse and neglect. Journal of Family Violence, 13, 147162.

Mandell, D. S., Novak, M. M., \& Zubritsky, C. D. (2005). Factors associated with age of diagnosis among children with autism spectrum disorders. Pediatrics, 116, 1480-1486. doi: 10.1542/peds.2005-0185

Meadan, H., Halle, J. W. \& Ebata, A. T., (2010). Families with children who have autism spectrum disorders: Stress and support. Exceptional Children, 77, 7-36. 
Moes, D. R., \& Frea, W. R. (2002). Contextualized behavioral support in early intervention for children with autism and their families. Journal of Autism \& Developmental Disorders, $32,519-533$.

Montes, G., Halterman, J., \& Magyar, C. (2009). Access to and satisfaction with school and community health services for us children with ASD. Pediatrics, 124, S407-S413. doi:10.1542/peds.2009-1255L.

National Autism Center (NAC). (2009). National standard report: Addressing the need for evidence-based practice guidelines for autism spectrum disorders. Randolph MA: National Autism Center.

National Research Council. (2001). Educating children with autism. Committee on Educational Interventions for Children with Autism. C. Lord \& J. P. McGee (Eds.) Washington DC: National Academy Press, Division of Behavioral and Social Sciences and Education.

Nefdt, N., Koegel, R., Singer, G., \& Gerber, M. (2010). The use of a self-directed learning program to provide introductory training in pivotal response treatment to parents of children with autism. Journal of Positive Behavior Interventions, 12, 23-32.

Nunes, D., \& Hanline, M. F. (2007). Enhancing the alternative and augmentative communication use of a child with autism through a parent-implemented naturalistic intervention. International Journal of Disability, Development \& Education, 54, 177-197. doi:10.1080/10349120701330495 
Osborne, L., \& Reed, P. (2009). The relationship between parenting stress and behavior problems of children with autistic spectrum disorders. Exceptional Children, 76, 5473.

Pacifici, C., Delaney, R., White, L., Nelson, C., \& Cummings, K. (2006). Web-based training for foster, adoptive, and kinship parents. Children \& Youth Services Review, 28, 1329-1343. doi: 10.1016/j.childyouth.2006.02.003

Parette, H. P., Meadan, H., Doubet, S., \& Hess, J. (2010). Supporting families of young children with disabilities using technology. Education and Training in Autism and Developmental Disabilities, 45, 552-565.

Peishi, W. (2008). Effects of a parent-training program on the interactive skills of parents of children with autism in China. Journal of Policy \& Practice in Intellectual Disabilities, 5, 96-104. doi:10.1111/j.1741-1130.2008.00154.x

Petalas, M. A., Hastings, R. P., Nash, S., Dowey, A., \& Reilly, D. (2009). "I like that he always shows who he is": The perceptions and experiences of siblings with a brother with autism spectrum disorder. International Journal of Disability, Development \& Education, 56, 381-399. doi:10.1080/10349120903306715

Reagon, K. A., \& Higbee, T. S. (2009). Parent-implemented script fading to promote play-based verbal initiations in children with autism. Journal of Applied Behavior Analysis, 42, 659-664. doi:10.1901/jaba.2009.42-659

Reischl, U., \& Oberleitner, R. (2009). Development of a telemedicine platform for the management of children with autism. German Journal for Young Researchers / Zeitschrift für Nachwuchswissenschafter, 1, 23-29. 
Richards, J. C., \& Alvarenga, M. E. (2002). Extension and replication of an internet-based treatment program for panic disorder. Cognitive Behaviour Therapy, 31, 41-47. doi:10.1080/16506070252823652

Rogers, S. J., \& Vismara, L. A. (2008). Evidence-based comprehensive treatments for early autism. Journal of Clinical Child \& Adolescent Psychology, 37, 8-38. doi: $10.1080 / 15374410701817808$

Rule, S., Salzberg, C., Higbee, T., Menlove, R., \& Smith, J. (2006). Technology-mediated consultation to assist rural students: A case study. Rural Special Education Quarterly, $25,3-7$.

Sanders, M., Calam, R., Durand, M., Liversidge, T., \& Carmont, S. A. (2008). Does self-directed and web-based support for parents enhance the effects of viewing a reality television series based on the Triple $\mathrm{P}$ - Positive Parenting Programme? Journal of Child Psychology \& Psychiatry, 49, 924-932. doi: 10.1111/j.1469-7610.2008.01901.x

Schertz, H. H., \& Odom, S. L. (2007). Promoting joint attention in toddlers with autism: A parent- mediated developmental model. Journal of Autism \& Developmental Disorders, 37, 1562-1575. doi: 10.1007/s10803-006-0290-z

Schieve, L. A., Blumberg, S. J., Rice, C., Visser, S. N., \& Boyle, C. (2007). The relationship between autism and parenting stress. Pediatrics, 119, S114-S121. doi: 10.1542/peds.2006-2089Q.

Seung, H., Ashwell, S., Elder, J., \& Valcante, G. (2006). Verbal communication outcomes in children with autism after in-home father training. Journal of Intellectual Disability Research, 50, 139-150. doi:10.1111/j.1365-2788.2005.00767.x. 
Sebastian, J. P., Egan, W. M., \& Mayhew, J. C. (2009). From two-way television to the Internet: The evolution of a rural distance education program. Rural Special Education Quarterly, 28(3), 5-8.

Sharry, J., Guerin, S., Griffin, C., \& Drumm, M. (2005). An evaluation of the parents plus early years programme: A video-based early intervention for parents of pre-school children with behavioural and developmental difficulties. Clinical Child Psychology \& Psychiatry, 10, 319-336. doi: 10.1177/1359104505053752

Smedley, T. M., \& Higgins, K. (2005). Virtual technology: Bringing the world into the special education classroom. Intervention in School \& Clinic, 41, 114-119.

Smith, S. M. (2007). Visual supports: Online training module (Columbus: Ohio Center for Autism and Low Incidence). In Ohio Center for Autism and Low Incidence (OCALI). Autism Internet Modules, www.autisminternetmodules.org. Columbus, OH: OCALI

Smith, S., \& Meyen, E. (2003). Applications of online instruction: An overview for teachers, students with mild disabilities, and their parents. Focus on Exceptional Children, 35(6), 1-15.

Solomon, M., Ono, M., Timmer, S., \& Goodlin-Jones, B. (2008). The effectiveness of parentchild interaction therapy for families of children on the autism spectrum. Journal of Autism \& Developmental Disorders, 38, 1767-1776. doi:10.1007/s10803-008-0567-5

Solomon, R., Necheles, J., Ferch, C., Bruckman, D. (2007). Pilot study of a parent-training program for young children with autism: The PLAY project home consultation program. Autism: The International Journal of Research \& Practice, 11, 205-224. doi:

$10.1177 / 1362361307076842$ 
Stahmer, A. C., \& Gist, K. (2001). The effects of an accelerated parent education program on technique mastery and child outcome. Journal of Positive Behavior Interventions, 3, 75.

Stenberg, P. L., \& Low, Sarah A., (2009, February). Rural broadband at a glance 2009: Edition economic information bulletin (Issue Brief No. 47). Retrieved from Social Science Research Network: http://ssrn.com/abstract=1400988

Symon, J. B. (2001). Parent education for autism: Issues in providing services at a distance. Journal of Positive Behavior Interventions, 3, 160-174.

Symon, J. B. (2005). Expanding interventions for children with autism: Parents as trainers. Journal of Positive Behavior Interventions, 7, 159-173.

Tarbox, J., Schiff, A., \& Najdowski, A. C. (2010). Parent-implemented procedural modification of escape extinction in the treatment of food selectivity in a young child with autism. Education \& Treatment of Children, 33, 223-234.

The Center for Rural Pennsylvania (2010) Rural/Urban PA. Retrieved from http://www.rural.palegislature.us/rural_urban.html

Thomas, K. C., Ellis, A. R., McLaurin, C., Daniels, J., \& Morrissey, J. P. (2007). Access to care for autism-related services. Journal of Autism \& Developmental Disorders, 37, 19021912. doi: 10.1007/s10803-006-0323-7

Twoy, R., Connolly, P. M., \& Novak, J. M. (2007). Coping strategies used by parents of children with autism. Journal of the American Academy of Nurse Practitioners, 19, 251-260. doi: $10.1111 / \mathrm{j} .1745-7599.2007 .00222 . x$ 
Vismara, L. A., Colombi, C., \& Rogers, S. J. (2009). Can one hour per week of therapy lead to lasting changes in young children with autism? Autism: The International Journal of Research \& Practice, 13, 93-115. doi: 10.1177/1362361307098516

Vismara, L. A., Young, G. S., Stahmer, A. C., Griffith, E., \& Rogers, S. J. (2009). Dissemination of evidence-based practice: Can we train therapists from a distance? Journal of Autism \& Developmental Disorders, 39(12), 1636-1651. doi:10.1007/s10803-009-0796-2

Wang, P., Michaels, C. A., \& Day, M. S. (2011). Stresses and coping strategies of Chinese families with children with autism and other developmental disabilities. Journal of Autism \& Developmental Disorders, 41, 783-795. doi:10.1007/s10803-010-1099-3

Whittingham, K., Sofronoff, K., Sheffield, J., \& Sanders, M. R. (2009). Stepping Stones Triple P: An RCT of a parenting program with parents of a child diagnosed with an autism spectrum disorder. Journal of Abnormal Child Psychology, 37, 469-480. doi:10.1007/s10802-008-9285-X

Woods, J. J., \& Wetherby, A. M. (2003). Early identification of and intervention for infants and toddlers who are at risk for autism spectrum disorder. Language, Speech \& Hearing Services in Schools, 34, 180-193.

Zahn, G., \& Buchanan, M. (2002). Supporting teachers of children with autism using distance education and video portfolios. Rural Special Education Quarterly, 21(4), 2125. 
Appendices 
Appendix A 
Dear Participant,

This letter is a request for you to take part in a research project to assess the outcome of using a self-directed, online program to provide training in visual supports to parents of children with autism. Parents will be self-directed through an online training module. The researcher, via

phone or email, will provide additional support to parents. Jennifer Suppo, M.Ed. in the Office of Special Education at West Virginia University (WVU), is conducting this project under the supervision of Dr. Michael Mayton, an assistant professor in the College of Human Resources and Education, for a Doctorate Degree in Special Education.

The self-directed, online program will give you information on the use and creation of visual supports that we expect will enable you to create them for your child, which in turn, can help your child gain a better understanding of his/her environment. Your participation in this project is greatly appreciated and the project will take approximately a total of 2 hours over a 1-3 week period to complete both the self-directed training and related activities. All training and related activities can be completed within the comfort of your own home.

In order to participate:

1. Your child must have a child diagnose of an autism spectrum disorder.

2. Your must have not participated in any formalized parent training on the use of visual supports.

3. You must either be on waiting list for services at the time of the intervention and/or live in a rural area or you have had difficulty being able to attend a parent training concerning your child with autism because of the lack of availability of services or opportunities.

4. You must have access to both a computer and an Internet connection.

The study will require you to:

1. Complete paperwork (e.g., pre/posttest and create a visual support)

2. Complete an online training module. 
Your participation is completely voluntary. I hope that you will participate in this research project, as it could be beneficial in providing additional parent training opportunities to families who have children diagnosed with autism. Thank you very much for your time. Should you have any questions or would like to participate in the study please feel free to contact Jennifer Suppo at (724) 396-1133 or by email at jsuppo@mix.wvu.edu. Thank you for your time and help with this project.

Sincerely,

Jennifer Suppo

Figure 4. Invitation to Participate In Study 


\section{Parent Demographic Form}

All information will be kept confidential. The information provided will help us have a better understanding of the results of the study. Thank you for your participation!

1. Your Name:

2. Your Age:

3. Your Gender (circle one): $\mathrm{M}$ or $\mathrm{F}$

4. How did you hear about the study? (circle all that apply)

Support group

Doctor's office

Educational agency (e.g., intermediate unit, school district)

Other: (please specify)

5. Participants Ethnicity (circle one):

African American

Hispanic

Asian American

White

Other (please specify): 
6. Marital Status (circle one):

Married

Divorced

Separated

Widowed

Single

Living with Significant Other

7. Community you live in (circle one):

Rural area (Including rural counties and or school districts)

Town

Small City

Metropolitan area

8. Please write the state and county in which you live in the space provided.

State:

County:

9. Household income (circle one):

Less than 20,000

20,000-34,999

$35,000-49,000$

$50,000-74,999$

Over 75,000 
10. Are you on a waiting list for services (circle one)?

Yes

No

11. Have you had difficulty or do you believe that you are missing important parent training opportunities on autism because of lack of availability of services (circle one)?

Yes

No

12. Age of your child with autism: Years

Months

13. Gender of your child with autism(circle one): $\mathrm{M}$ or F

14. What is your relationship to the child? (circle one)

Mom

Dad

Other (please specify)

15. Does your child live in the same home as you?

Yes

No

16. What services does your child currently receive? (circle all that apply)

None

Occupational Therapy

Speech Therapy

Special Education (location of services):

Other:

Figure 5. Parent Demographic Form 
Appendix B 


\section{Pretest}

\section{Participant Name:}

\section{PLEASE COMPLETE THE PRETEST AND SEND IT BACK TO THE RESEARCHER IN THE PREPAID ENVELOP WITHIN 5 DAYS OF RECEIVING IT.}

Please do not look up answers to the questions so your answers in both the pretest and posttest accurately reflect what you learn.

Thank you!!

1. Visual supports are used only in the school environment. (Circle one)
A. True
B. False

2. Visual supports can be developed for (Circle one)
A. A group of individuals
B. An Individual
C. Both
D. None of the above

3. A visual support is (Circle one)
A. A picture or photograph
B. A tool or symbol presented visually
C. Text accompanied by a picture of graphic
D. A picture, photo or graphic but does not include written words 
4. Visual supports are only used to help individuals who are having behavioral difficulty (Circle one)
A. True
B. False

5. Labels and locators are only used by individuals with disabilities (Circle one)
A. True
B. False

6. Visual boundaries are only used when working with very young children and should be discontinued as a child gets older. (Circle one)
A. True
B. False

7. Once an individual uses a visual support independently, it should be faded. (Circle one)
A. True, visual supports should always be faded
B. False, visual supports should never be faded
C. It depends on how big the support is and if it is hard to carry
D. Fading is based on the needs of the individual 
8. Put in order (number 1-4) the following steps for setting up a visual boundary. Teach the boundary

Define the need

Evaluate Success

Define the boundary

9. The ultimate goal of using visual supports is independence. (Circle one)
A. True
B. False

10. If a child does not seem to notice that you have labeled everything to organize the child's environment then you should stop using labels. (Circle one)
A. True
B. False

\section{* Please return Pretest in prepaid envelope within 5 days of}

\section{receiving. Thank you!}

The preceding was adapted from:

Smith, S. M. (2007). Visual supports: Online training module (Columbus: Ohio Center for Autism and Low Incidence). In Ohio Center for Autism and Low Incidence (OCALI). Autism Internet Modules, www.autisminternetmodules.org. Columbus, OH: OCALI 


\section{Pretest}

\section{Participant Name:}

\section{PLEASE COMPLETE THE PRETEST AND SEND IT BACK TO THE RESEARCHER IN THE PREPAID ENVELOP WITHIN 5 DAYS OF RECEIVING IT.}

Please do not look up answers to the questions so your answers in both the pretest and posttest accurately reflect what you learn.

Thank you!!

1. Visual supports are used only in the school environment. (Circle one)
A. True
B. False

2. Visual supports can be developed for (Circle one)
A. A group of individuals
B. An Individual
C. Both
D. None of the above

3. A visual support is (Circle one)
A. A picture or photograph
B. A tool or symbol presented visually
C. Text accompanied by a picture of graphic
D. A picture, photo or graphic but does not include written words 
4. Visual supports are only used to help individuals who are having behavioral difficulty (Circle one)
A. True
B. False

5. Labels and locators are only used by individuals with disabilities (Circle one)
A. True
B. False

6. Visual boundaries are only used when working with very young children and should be discontinued as a child gets older. (Circle one)
A. True
B. False

7. Once an individual uses a visual support independently, it should be faded. (Circle one)
A. True, visual supports should always be faded
B. False, visual supports should never be faded
C. It depends on how big the support is and if it is hard to carry
D. Fading is based on the needs of the individual 
8. Put in order (number 1-4) the following steps for setting up a visual boundary.

3_ Teach the boundary

_1_ Define the need

4__ Evaluate Success

___ Define the boundary

9. The ultimate goal of using visual supports is independence. (Circle one)
A. True
B. False

10. If a child does not seem to notice that you have labeled everything to organize the child's environment then you should stop using labels. (Circle one)
A. True
B. False

\section{* Please return Pretest in prepaid envelope within 5 days of}

\section{receiving. Thank you!}

The preceding was adapted from:

Smith, S. M. (2007). Visual supports: Online training module (Columbus: Ohio Center for Autism and Low Incidence). In Ohio Center for Autism and Low Incidence (OCALI). Autism Internet Modules, www.autisminternetmodules.org. Columbus, OH: OCALI 
$\underline{\text { Posttest }}$

\section{Participant Name:}

PLEASE COMPLETE THE POSTTEST AND SEND IT BACK TO THE RESEARCHER IN THE PREPAID ENVELOP WITHIN 5 DAYS OF RECEIVING IT.

Please do not look up answers to the questions so your answers in both the pretest and posttest accurately reflect what you learn.

Thank you!!

1. Visual supports can be developed for (Circle one)
A. An Individual
B. A group of individuals
C. Both
D. None of the above

2. Visual supports are used only in the home environment. (Circle one)
A. False
B. True

3. Visual supports are only used to help individuals who are having communication difficulty (Circle one)
A. True
B. False 
4. Put in order (number 1-4) the following steps for setting up a visual boundary. Teach the boundary

Evaluate Success

Define the boundary

Define the need

5. The ultimate goal of using visual supports is independence. (Circle one)
A. True
B. False

6. A visual support is (Circle one)
A. A picture, photo or graphic but does not include written words
B. A tool or symbol presented visually
C. A picture or photograph
D. Text accompanied by a picture of graphic

7. Labels and locators are only used by individuals with disabilities (Circle one)
A. True
B. False 
8. Visual boundaries are only used when working with very young children and should be discontinued as a child gets older. (Circle one)
A. False
B. True

9. Once an individual uses a visual support independently, it should be faded. (Circle one)
A. True, visual supports should always be faded
B. Fading is based on the needs of the individual
C. It depends on how big the support is and if it is hard to carry
D. False, visual supports should never be faded

10. If a child does not seem to notice that you have labeled everything to organize the child's environment then you should stop using labels. (Circle one)
A. False
B. True

\section{* Please return Posttest in prepaid envelope within 5 days of}

\section{receiving. Thank you!}

The preceding was adapted from:

Smith, S. M. (2007). Visual supports: Online training module (Columbus: Ohio Center for

Autism and Low Incidence). In Ohio Center for Autism and Low Incidence (OCALI). Autism Internet Modules, www.autisminternetmodules.org. Columbus, OH: OCALI 
$\underline{\text { Posttest }}$

\section{Participant Name:}

PLEASE COMPLETE THE POSTTEST AND SEND IT BACK TO THE RESEARCHER IN THE PREPAID ENVELOP WITHIN 5 DAYS OF RECEIVING IT.

Please do not look up answers to the questions so your answers in both the pretest and posttest accurately reflect what you learn.

Thank you!!

1. Visual supports can be developed for (Circle one)
A. An Individual
B. A group of individuals
C. Both
D. None of the above

2. Visual supports are used only in the home environment. (Circle one)
A. False
B. True

3. Visual supports are only used to help individuals who are having communication difficulty (Circle one)
A. True
B. False 
4. Put in order (number 1-4) the following steps for setting up a visual boundary.

3_ Teach the boundary

_4_ Evaluate Success

_2_ Define the boundary

_1_ Define the need

5. The ultimate goal of using visual supports is independence. (Circle one)
A. True
B. False

6. A visual support is (Circle one)
A. A picture, photo or graphic but does not include written words
B. A tool or symbol presented visually
C. A picture or photograph
D. Text accompanied by a picture of graphic

7. Labels and locators are only used by individuals with disabilities
A. True
B. False 
8. Visual boundaries are only used when working with very young children and should be discontinued as a child gets older. (Circle one)
A. False
B. True

9. Once an individual uses a visual support independently, it should be faded. (Circle one)
A. True, visual supports should always be faded
B. Fading is based on the needs of the individual
C. It depends on how big the support is and if it is hard to carry
D. False, visual supports should never be faded

10. If a child does not seem to notice that you have labeled everything to organize the child's environment then you should stop using labels. (Circle one)
A. False
B. True

\section{* Please return Posttest in prepaid envelope within 5 days of}

\section{receiving. Thank you!}

The preceding was adapted from:

Smith, S. M. (2007). Visual supports: Online training module (Columbus: Ohio Center for Autism and Low Incidence). In Ohio Center for Autism and Low Incidence (OCALI). Autism Internet Modules, www.autisminternetmodules.org. Columbus, OH: OCALI

Figure 6. Pretest and Posttest 


\section{Parent Training Booklet}




\section{Parent Training Index}

Overall Study Participant Directions...................................... 2

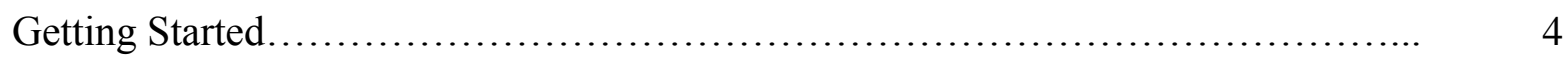

Parent Clarification Protocol............................................... 6

Parent Training Checklist................................................ 7 


\section{READ FIRST}

\section{Overall Study Participant Directions:}

1. Complete and send back the Pretest in prepaid envelope within 5 days of receiving.

2. When the researcher receives your Pretest, the researcher will send you the training package and case-study activity.

3. Upon receiving the training package, you have $\mathbf{1}$ week to complete and send back the online training package in the prepaid envelope.

4. Included with the online training package is contact with the researcher by email or by phone to provide clarification on the online training module. You can email me at jsuppo@ mix.wvu.edu or call me at 724-396-1133. However, the researcher cannot provide additional training (See Parent Clarification Protocol Located within this training package for further details)

5. Upon completing the online training package you have $\mathbf{1}$ week to complete and send back the case-study activity in the prepaid 
envelope (this will arrive in your parent training package; however Do Not Open until you complete the training).

6. When the researcher receives your completed training package, the researcher will send you the Posttest and the Parent Survey to complete and send back in a prepaid envelope within 5 days.

\section{OK....Let's Begin (turn to the next page)}




\section{Get Started: To Start Online Training Module}

1. Turn on your computer and type in following website:

http://www.autisminternetmodules.org/

****If you have signed up with your email account and created a password then go to \# 4 .

2. Under the words Welcome to AIM click on "create an account"

3. Under the words Sign up fill in the *required fields (choose a password you will remember and write it down). Completion of the Sign Up will take you directly into the site to get started. If you are going to start the training, immediately go to \#5 and skip \#4.

4. If you have already signed up prior to beginning the training then log onto the Autism Internet Modules by placing your email address and password in the spaces provided on the left side of the page.

5. Click on the autism at home which is a green tab in the middle of the page.

6. Scroll down and click on "Visual Supports"

7. Next, click on "Enter Module"

8. Follow the Parent Training Checklist. Please only complete the parts of the module that the Parent Training Checklist says to complete. You have 1 week to complete the entire module and send back to the researcher in the 
prepaid envelope. You can complete the training at any time of the day or night and over multiple days at your own convenience during the 1 week. You will receive a Posttest and Parent Survey in the mail upon completion and sending in of the Parent Training Checklist. You have 5 day to complete and send back both the Posttest and checklist. Thank You!

9. Once you have completed and sent back the Parent Training Checklist go onto the the Case-Study: Visual Support Creation (the Case-Study: Visual Support Creation was located within the Parent Training Checklist package). You have 1 week from sending back the Parent Training Checklist to complete and send your created visual support in the prepaid envelope. 


\section{Parent Clarification Protocol (What the researcher can and cannot help you with)}

The researcher shall provide the following clarification support for the participant(s):

1. The researcher can answer questions on location of information in the module if the participant does not find the location of a section of the module while following the prescribed checklist. For example, if the parent checklist says for a parent to go to the Introduction and the parent cannot find the location of the Introduction then the researcher can walk a parent through how to find the location of the Introduction.

2. The researcher can provide an equivalent home example of an idea or concept in the module if the module provides an example that is presented as an example to provide support for a child in school, however, does not provide an example of the concept in a home setting. For example, if the module suggests color-coding a morning schedule and afternoon schedule to relay to the student the time of day of an activity, the researcher can provide an equivalent home example, if one is not provided, on color-coding a morning schedule and afternoon schedule to relay to the child at home the time of day of an activity.

3. The researcher can explain a meaning of a word. For example, if the parent does not know the meaning of the word synonymously, then the researcher can provide them with a dictionary definition.

The researcher will not provide the following additional training for the participant(s):

1. The researcher will not provide additional training beyond that prescribed for the online module.

2. The researcher will not suggest additional sites of training for visual supports if asked by the participants until after the participant has completed the study. 


\section{Parent Training Checklist}

Participant Name:

Parent Training Checklist: Please fill out each section as you move through the training. Thank you!!!

If you need clarification on the module, please contact Jennifer Suppo at jsuppo@ mix.wvu.edu or 724-396-1133.

\begin{tabular}{|c|c|c|c|c|c|}
\hline Module Activity & $\begin{array}{l}\text { Time } \\
\text { Start }\end{array}$ & $\begin{array}{l}\text { Time } \\
\text { Stop }\end{array}$ & $\begin{array}{l}\text { Date } \\
\text { Start }\end{array}$ & $\begin{array}{l}\text { Date } \\
\text { Complete }\end{array}$ & $\begin{array}{l}\text { Did you need } \\
\text { additional } \\
\text { clarification } \\
\text { from Jennifer } \\
\text { Suppo? } \\
\text { (yes/no) }\end{array}$ \\
\hline 1. Introduction: & & & & & \\
\hline $\begin{array}{l}\text { a. Watch the Movie: Visual } \\
\text { Supports - Introduction }\end{array}$ & & & & & Yes or No \\
\hline \multicolumn{6}{|l|}{$\begin{array}{l}\text { * Do Not Take Pretest: Mo } \\
\text { to starting the Module) }\end{array}$} \\
\hline \multicolumn{6}{|l|}{ 2. Overview: } \\
\hline a. Read through Overview & & & & & Yes or No \\
\hline b. View pictures on Overview page & & & & & Yes or No \\
\hline
\end{tabular}




\begin{tabular}{|c|c|c|c|c|c|}
\hline Module Activity & $\begin{array}{l}\text { Time } \\
\text { Start }\end{array}$ & $\begin{array}{l}\text { Time } \\
\text { Stop }\end{array}$ & $\begin{array}{l}\text { Date } \\
\text { Start }\end{array}$ & $\begin{array}{l}\text { Date } \\
\text { Complete }\end{array}$ & $\begin{array}{l}\text { Did you need } \\
\text { additional } \\
\text { clarification } \\
\text { from Jennifer } \\
\text { Suppo? } \\
\text { (yes/no) }\end{array}$ \\
\hline $\begin{array}{l}\text { c. Click and read each Page } \\
\text { Keyword located on right-hand } \\
\text { side of the page (Accommodate, } \\
\text { ASD, Autism Spectrum } \\
\text { Disorder, Visual Supports, } \\
\text { Visual Symbols) }\end{array}$ & & & & & Yes or No \\
\hline \multicolumn{6}{|l|}{ 3. Module Objectives: } \\
\hline a. Read through Module Objectives & & & & & Yes or No \\
\hline \multicolumn{6}{|l|}{ 4. CEC Professional Standards: } \\
\hline \multicolumn{6}{|c|}{ a. Read through CEC Professional Standards } \\
\hline \multicolumn{6}{|c|}{ 5. Defining Visual Supports: } \\
\hline $\begin{array}{l}\text { a. Read through Defining Visual } \\
\text { Supports }\end{array}$ & & & & & Yes or No \\
\hline $\begin{array}{l}\text { b. View pictures on Defining } \\
\text { Visual Supports page }\end{array}$ & & & & & Yes or No \\
\hline $\begin{array}{l}\text { c. Click and read each Page } \\
\text { Keyword located on right-hand } \\
\text { side of the page (Label, Map, } \\
\text { Organization System, Schedule, } \\
\text { Script, Timeline, Visual } \\
\text { Boundary, Visual Cue, Visual } \\
\text { Strategies, Visual Supports) }\end{array}$ & & & & & Yes or No \\
\hline
\end{tabular}




\begin{tabular}{|c|c|c|c|c|c|}
\hline Module Activity & $\begin{array}{l}\text { Time } \\
\text { Start }\end{array}$ & $\begin{array}{l}\text { Time } \\
\text { Stop }\end{array}$ & $\begin{array}{l}\text { Date } \\
\text { Start }\end{array}$ & $\begin{array}{l}\text { Date } \\
\text { Complete }\end{array}$ & $\begin{array}{l}\text { Did you need } \\
\text { additional } \\
\text { clarification } \\
\text { from Jennifer } \\
\text { Suppo? } \\
\text { (yes/no) }\end{array}$ \\
\hline \multicolumn{6}{|l|}{ 6. Creating Visual Boundaries } \\
\hline $\begin{array}{l}\text { a. Read through Creating Visual } \\
\text { Boundaries }\end{array}$ & & & & & Yes or No \\
\hline $\begin{array}{l}\text { b. Click and read each Page } \\
\text { Keyword located on right-hand } \\
\text { side of the page (Visual } \\
\text { Boundary) }\end{array}$ & & & & & Yes or No \\
\hline \multicolumn{6}{|c|}{$\begin{array}{l}\text { 7. Steps for Setting up Visual Boundaries (Have to click on Creating Visual Boundaries } \\
1^{\text {st }} \text { and underneath is Steps for Setting up Visual Boundaries) }\end{array}$} \\
\hline $\begin{array}{l}\text { a. Read through Steps for Setting } \\
\text { up Visual Boundaries }\end{array}$ & & & & & Yes or No \\
\hline $\begin{array}{l}\text { b. View pictures on Steps for } \\
\text { Setting up Visual Boundaries } \\
\text { page }\end{array}$ & & & & & Yes or No \\
\hline $\begin{array}{l}\text { c. Click and read each Page } \\
\text { Keyword located on right-hand } \\
\text { side of the page (Accessible, } \\
\text { Appropriate Behavior, } \\
\text { Compliance, Consistent, } \\
\text { Evaluate, Expectation, Group } \\
\text { Area, Individualization, } \\
\text { Interventions, Model or } \\
\text { Modeling, Organization System, } \\
\text { Paraeducator, Play Area, } \\
\text { Reinforcement, Self- } \\
\text { Verbalization Technique, } \\
\text { Strategies, Visual Boundary, } \\
\text { Visually Defined, Work Area) }\end{array}$ & & & & & Yes or No \\
\hline
\end{tabular}




\begin{tabular}{|l|l|l|l|l|l|}
\hline & & & & Did you need \\
& additional \\
clarification \\
from Jennifer \\
\end{tabular}




\begin{tabular}{|c|c|c|c|c|c|}
\hline Module Activity & $\begin{array}{l}\text { Time } \\
\text { Start }\end{array}$ & $\begin{array}{l}\text { Time } \\
\text { Stop }\end{array}$ & $\begin{array}{l}\text { Date } \\
\text { Start }\end{array}$ & $\begin{array}{l}\text { Date } \\
\text { Complete }\end{array}$ & $\begin{array}{l}\text { Did you need } \\
\text { additional } \\
\text { clarification } \\
\text { from Jennifer } \\
\text { Suppo? } \\
\text { (yes/no) }\end{array}$ \\
\hline b. View pictures on Locator page & & & & & Yes or No \\
\hline $\begin{array}{l}\text { c. Click and read each Page } \\
\text { Keyword located on right-hand } \\
\text { side of the page (Locator, Visual } \\
\text { Schedule, Visual Tool) }\end{array}$ & & & & & Yes or No \\
\hline \multicolumn{6}{|l|}{ 12. Defining Visual Schedules } \\
\hline $\begin{array}{l}\text { a. Read through Defining Visual } \\
\text { Schedules }\end{array}$ & & & & & Yes or No \\
\hline $\begin{array}{l}\text { b. View picture on Defining Visual } \\
\text { Schedules page }\end{array}$ & & & & & Yes or No \\
\hline $\begin{array}{l}\text { c. Watch the Movie: The } \\
\text { Importance of Visual Schedules }\end{array}$ & & & & & Yes or No \\
\hline $\begin{array}{l}\text { d. Click and read each Page } \\
\text { Keyword located on right-hand } \\
\text { side of the page (Icon, Visual } \\
\text { Schedule) }\end{array}$ & & & & & Yes or No \\
\hline \multicolumn{6}{|c|}{$\begin{array}{l}\text { 13. Group Schedules (You have to click on Defining Visual Schedules } 1^{\text {st }} \text { and underneath is } \\
\text { Group Schedules) }\end{array}$} \\
\hline a. Read through Group Schedules & & & & & Yes or No \\
\hline $\begin{array}{l}\text { b. View picture on Group } \\
\text { Schedules }\end{array}$ & & & & & Yes or No \\
\hline $\begin{array}{l}\text { c. Click and read each Page } \\
\text { Keyword located on right-hand } \\
\text { side of the page (Group } \\
\text { Schedule, Icon) }\end{array}$ & & & & & Yes or No \\
\hline $\begin{array}{l}\text { 14. Individual Schedules (You hav } \\
\text { underneath is Individual Schedu }\end{array}$ & lick & 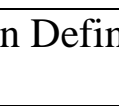 & $\mathrm{g} \mathrm{Vi}$ & Schedu & st and \\
\hline
\end{tabular}




\begin{tabular}{|c|c|c|c|c|c|}
\hline Module Activity & $\begin{array}{l}\text { Time } \\
\text { Start }\end{array}$ & $\begin{array}{l}\text { Time } \\
\text { Stop }\end{array}$ & $\begin{array}{l}\text { Date } \\
\text { Start }\end{array}$ & $\begin{array}{l}\text { Date } \\
\text { Complete }\end{array}$ & $\begin{array}{l}\text { Did you need } \\
\text { additional } \\
\text { clarification } \\
\text { from Jennifer } \\
\text { Suppo? } \\
\text { (yes/no) }\end{array}$ \\
\hline $\begin{array}{l}\text { a. Watch the Movie: Visual } \\
\text { Schedules: Photos and Line } \\
\text { Drawings }\end{array}$ & & & & & Yes or No \\
\hline $\begin{array}{l}\text { b. Read through Individual } \\
\text { Schedules }\end{array}$ & & & & & Yes or No \\
\hline $\begin{array}{l}\text { c. View pictures on Individual } \\
\text { Schedules }\end{array}$ & & & & & \\
\hline $\begin{array}{l}\text { d. Watch the Movie: Visual } \\
\text { Supports: Object Schedule }\end{array}$ & & & & & Yes or No \\
\hline $\begin{array}{l}\text { e. Click and read each Page } \\
\text { Keyword located on right-hand } \\
\text { side of the page (Individual } \\
\text { Schedule) } \\
\end{array}$ & & & & & Yes or No \\
\hline \multicolumn{6}{|c|}{$\begin{array}{l}\text { 15. Schedules in the Home, Work or Community (You have to click on Defining Visual } \\
\text { Schedules } 1^{\text {st }} \text { and underneath is Schedules in the Home, Work or Community) }\end{array}$} \\
\hline $\begin{array}{l}\text { a. Watch the Movie: Visual } \\
\text { Supports: First-Then and } \\
\text { Matching Schedules }\end{array}$ & & & & & Yes or No \\
\hline $\begin{array}{l}\text { b. Read through Schedules in the } \\
\text { Home, Work or Community }\end{array}$ & & & & & Yes or No \\
\hline $\begin{array}{l}\text { c. View picture on Schedules in the } \\
\text { Home, Work or Community }\end{array}$ & & & & & \\
\hline $\begin{array}{l}\text { d. Click and read each Page } \\
\text { Keyword located on right-hand } \\
\text { side of the page (Schedule, } \\
\text { Visual Supports) } \\
\end{array}$ & & & & & Yes or No \\
\hline
\end{tabular}




\begin{tabular}{|c|c|c|c|c|c|}
\hline Module Activity & $\begin{array}{l}\text { Time } \\
\text { Start }\end{array}$ & $\begin{array}{l}\text { Time } \\
\text { Stop }\end{array}$ & $\begin{array}{l}\text { Date } \\
\text { Start }\end{array}$ & $\begin{array}{l}\text { Date } \\
\text { Complete }\end{array}$ & $\begin{array}{l}\text { Did you need } \\
\text { additional } \\
\text { clarification } \\
\text { from Jennifer } \\
\text { Suppo? } \\
\text { (yes/no) }\end{array}$ \\
\hline \multicolumn{6}{|c|}{$\begin{array}{l}\text { 16. Tips for Creating Visual Schedules (You have to click on Defining Visual Schedules } 1^{\text {st }} \\
\text { and underneath is Tips for Creating Visual Schedules) }\end{array}$} \\
\hline $\begin{array}{l}\text { a. Read through Tips for Creating } \\
\text { Visual Schedules }\end{array}$ & & & & & Yes or No \\
\hline \multicolumn{6}{|l|}{$\begin{array}{l}\text { b. View pictures on Tips for } \\
\text { Creating Visual Schedules }\end{array}$} \\
\hline $\begin{array}{l}\text { e. Click and read each Page } \\
\text { Keyword located on right-hand } \\
\text { side of the page (Color-Coding, } \\
\text { Schedule, Visual Schedule, } \\
\text { Visual Supports) }\end{array}$ & & & & & Yes or No \\
\hline \multicolumn{6}{|c|}{ 17. Visual Supports for Less Structured Settings } \\
\hline $\begin{array}{l}\text { e. Read through Visual Supports } \\
\text { for Less Structured Settings }\end{array}$ & & & & & Yes or No \\
\hline $\begin{array}{ll}\text { f. } & \text { View pictures on Visual } \\
& \text { Supports for Less Structured } \\
\text { Settings page }\end{array}$ & & & & & Yes or No \\
\hline $\begin{array}{l}\text { g. Click and read each Page } \\
\text { Keyword located on right-hand } \\
\text { side of the page (Visual } \\
\text { Supports) }\end{array}$ & & & & & Yes or No \\
\hline \multicolumn{6}{|c|}{$\begin{array}{l}\text { 18. Transition Supports (You have to click on Visual Supports for Less Structured Settings } \\
1^{\text {st }} \text { and underneath is Transition Supports) }\end{array}$} \\
\hline $\begin{array}{l}\text { a. Read through Transition } \\
\text { Supports }\end{array}$ & & & & & Yes or No \\
\hline $\begin{array}{l}\text { b. View pictures on Transition } \\
\text { Supports page }\end{array}$ & & & & & Yes or No \\
\hline
\end{tabular}




\begin{tabular}{|c|c|c|c|c|c|}
\hline Module Activity & $\begin{array}{l}\text { Time } \\
\text { Start }\end{array}$ & $\begin{array}{l}\text { Time } \\
\text { Stop }\end{array}$ & $\begin{array}{l}\text { Date } \\
\text { Start }\end{array}$ & $\begin{array}{l}\text { Date } \\
\text { Complete }\end{array}$ & $\begin{array}{l}\text { Did you need } \\
\text { additional } \\
\text { clarification } \\
\text { from Jennifer } \\
\text { Suppo? } \\
\text { (yes/no) }\end{array}$ \\
\hline $\begin{array}{ll}\text { f. } & \text { Click and read each Page } \\
\text { Keyword located on right-hand } \\
\text { side of the page (Transition, } \\
\text { Transition Area, Transition Cue) }\end{array}$ & & & & & Yes or No \\
\hline \multicolumn{6}{|c|}{$\begin{array}{l}\text { 19. Community Supports (You have to click on Visual Supports for Less Structured } \\
\text { Settings } 1^{\text {st }} \text { and underneath is Community Supports) }\end{array}$} \\
\hline $\begin{array}{l}\text { a. } \text { Read through Community } \\
\text { Supports }\end{array}$ & & & & & Yes or No \\
\hline $\begin{array}{l}\text { b. View pictures on Community } \\
\text { Supports page }\end{array}$ & & & & & Yes or No \\
\hline $\begin{array}{l}\text { c. Click and read each Page } \\
\text { Keyword located on right-hand } \\
\text { side of the page (Visual } \\
\text { Supports) }\end{array}$ & & & & & Yes or No \\
\hline \multicolumn{6}{|c|}{$\begin{array}{l}\text { 20. Supports Outside the Classroom (You have to click on Visual Supports for Less } \\
\text { Structured Settings } 1^{\text {st }} \text { and underneath is Supports Outside the Classroom) }\end{array}$} \\
\hline $\begin{array}{l}\text { a. Read through Supports Outside } \\
\text { the Classroom }\end{array}$ & & & & & Yes or No \\
\hline $\begin{array}{l}\text { b. View pictures on Supports } \\
\text { Outside the Classroom page }\end{array}$ & & & & & Yes or No \\
\hline $\begin{array}{l}\text { c. Click and read each Page } \\
\text { Keyword located on right-hand } \\
\text { side of the page (Map, Mini- } \\
\text { Schedule, Schedule Within A } \\
\text { Schedule) }\end{array}$ & & & & & Yes or No \\
\hline \multicolumn{6}{|c|}{ 21. Visual Supports Across the Curriculum } \\
\hline $\begin{array}{l}\text { a. Read through Visual Supports } \\
\text { Across the Curriculum }\end{array}$ & & & & & Yes or No \\
\hline
\end{tabular}




\begin{tabular}{|c|c|c|c|c|c|}
\hline Module Activity & $\begin{array}{l}\text { Time } \\
\text { Start }\end{array}$ & $\begin{array}{l}\text { Time } \\
\text { Stop }\end{array}$ & $\begin{array}{l}\text { Date } \\
\text { Start }\end{array}$ & $\begin{array}{l}\text { Date } \\
\text { Complete }\end{array}$ & $\begin{array}{l}\text { Did you need } \\
\text { additional } \\
\text { clarification } \\
\text { from Jennifer } \\
\text { Suppo? } \\
\text { (yes/no) }\end{array}$ \\
\hline $\begin{array}{l}\text { b. View picture on Visual Supports } \\
\text { Across the Curriculum page }\end{array}$ & & & & & Yes or No \\
\hline $\begin{array}{l}\text { c. Watch the Movie: Visual } \\
\text { Supports: Transitions }\end{array}$ & & & & & Yes or No \\
\hline $\begin{array}{l}\text { d. } \text { Click and read each Page } \\
\text { Keyword located on right-hand } \\
\text { side of the page (Map, } \\
\text { Organization System, Timeline) }\end{array}$ & & & & & Yes or No \\
\hline \multicolumn{6}{|c|}{$\begin{array}{l}\text { 22. Graphic Organizers (You have to click on Visual Supports Across the Curriculum } 1^{\text {st }} \\
\text { and underneath is Graphic Organizers) }\end{array}$} \\
\hline $\begin{array}{ll}\text { a. } & \text { Read through Graphic } \\
\text { Organizers (Please Do Not go } \\
\text { onto view Inspriration and } \\
\text { Kidspiration software until } \\
\text { completion of the study) }\end{array}$ & & & & & Yes or No \\
\hline $\begin{array}{l}\text { b. View picture on Graphic } \\
\text { Organizers page }\end{array}$ & & & & & Yes or No \\
\hline $\begin{array}{l}\text { c. Click and read each Page } \\
\text { Keyword located on right-hand } \\
\text { side of the page (Graphic } \\
\text { Organizer) }\end{array}$ & & & & & Yes or No \\
\hline \multicolumn{6}{|c|}{$\begin{array}{l}\text { 23. Color-Coding (You have to click on Visual Supports Across the Curriculum } 1^{\text {st }} \text { and } \\
\text { underneath is Color-Coding) }\end{array}$} \\
\hline a. Read through Color-Coding & & & & & Yes or No \\
\hline $\begin{array}{l}\text { b. View picture on Color-Coding } \\
\text { page }\end{array}$ & & & & & Yes or No \\
\hline
\end{tabular}




\begin{tabular}{|c|c|c|c|c|c|}
\hline Module Activity & $\begin{array}{l}\text { Time } \\
\text { Start }\end{array}$ & $\begin{array}{l}\text { Time } \\
\text { Stop }\end{array}$ & $\begin{array}{l}\text { Date } \\
\text { Start }\end{array}$ & $\begin{array}{l}\text { Date } \\
\text { Complete }\end{array}$ & $\begin{array}{l}\text { Did you need } \\
\text { additional } \\
\text { clarification } \\
\text { from Jennifer } \\
\text { Suppo? } \\
\text { (yes/no) }\end{array}$ \\
\hline $\begin{array}{l}\text { c. } \text { Click and read each Page } \\
\text { Keyword located on right-hand } \\
\text { side of the page (Color-Coding) }\end{array}$ & & & & & Yes or No \\
\hline \multicolumn{6}{|c|}{$\begin{array}{l}\text { 24. Technology Supports (You have to click on Visual Supports Across the Curriculum } 1^{\text {st }} \\
\text { and underneath is Technology Supports) }\end{array}$} \\
\hline $\begin{array}{ll}\text { a. } & \text { Read through Technology } \\
\text { Supports }\end{array}$ & & & & & Yes or No \\
\hline $\begin{array}{l}\text { b. View pictures on Technology } \\
\text { Supports page }\end{array}$ & & & & & Yes or No \\
\hline \multicolumn{6}{|l|}{ 25. Summary } \\
\hline a. Read through Summary & & & & & Yes or No \\
\hline \multicolumn{6}{|c|}{ 26. Frequently Asked Questions (FAQs) } \\
\hline $\begin{array}{l}\text { a. Read through Frequently Asked } \\
\text { Questions (FAQ's) }\end{array}$ & & & & & Yes or No \\
\hline \multicolumn{6}{|c|}{$\begin{array}{l}\text { * Do Not Take Posttest located in the Module. You will take a Posttest that will be sent to } \\
\text { you upon completion of the training. }\end{array}$} \\
\hline \multicolumn{6}{|c|}{$\begin{array}{l}\text { *Send the Parent Training Checklist folder back to the researcher in the prepaid envelope } \\
\text { when you have completed the training within the 1-week period. }\end{array}$} \\
\hline
\end{tabular}

Next, open the envelope that came with your parent training folder that says:

Case-Study: Visual Support Creation and complete visual support creation activity.

Figure 7. Parent Training Package (The preceding has been adapted from the Ohio Department of Education OCALI website autism modules http://www.autisminternetmodules.org/) 
The following has been adapted from the Ohio Department of Education OCALI website http://www.autisminternetmodules.org/

Name:

1. Read the case study: Andrew.

2. Create a visual supports that may help Andrew based upon the information provided in the case example.

3. Write your answers to the questions at the end of the case study in the spaces provided.

4. Send the visual support and this paper with the case study that includes in writing your reason you chose the visual support you created in the prepaid envelop back to the researcher.

5. Contact the researcher if you have any questions at jsuppo@ mix.wvu.edu or call 724396-1133.

\section{CASE STUDY: ANDREW}

Andrew is a preschool student with Asperger Syndrome. His mother has decided to take turns carpooling Andrew and Jack, another student at Andrew's school, on Tuesday and Thursday because Jack's mom works those days. On Tuesday, Andrew's mom pulls into Jack's driveway, Jack gets in the van and sits next to Andrew. Andrew immediately tells Jack to get out of that seat, he does not belong in the car, and this is not his car. Andrew continues this behavior and it begins to escalate to a point that Andrew's mother has not seen before. She and Jack's mom decide that for today, Jack's mom will drive Jack.

This solution will not work for the long term though because Jack's mom needs to go to work. Andrew's mom is determined to find a solution that will help Andrew understand that Jack will be riding with them on Tuesday and Thursday.

Additional Information: Andrew relies on a schedule for his morning routine at home.

\section{After reading the case study, please complete the following:}


A. After reading about Andrew, use the information provided to create a visual support that could possibly help Andrew with this change.

B. Write what information you chose to present visually for Andrew on the lines provided:

C. Additionally, write the reason why it would help Andrew to have a visual support on the lines provided:

Figure 8. Case Study for Visual Support Creation 
Participant Number:

Reviewers Name:

\begin{tabular}{|c|c|c|c|}
\hline $\begin{array}{l}\text { Developing Visual Supports for Individual } \\
\text { Learner Based on the Provided Case-Study } \\
\text { (The checklist is created to evaluate the } \\
\text { provided case-study only and not intended for } \\
\text { use with other visual supports) }\end{array}$ & Yes & No & Notes/ Comments: \\
\hline
\end{tabular}

1. The participant's visual support includes 3 or more of the following pictorial representations:

\begin{tabular}{|c|c|}
\hline & $\begin{array}{l}\text { a pictorial representation of Jack } \\
\text { and/or }\end{array}$ \\
\hline b) & $\begin{array}{l}\text { a pictorial representation of Andrew } \\
\text { and/or }\end{array}$ \\
\hline c) & $\begin{array}{l}\text { a pictorial representation of a vehicle } \\
\text { or van and/or }\end{array}$ \\
\hline d) & $\begin{array}{l}\text { a pictorial representation of school or } \\
\text { preschool }\end{array}$ \\
\hline
\end{tabular}

2. The participant created a visual support that includes information the child needed to know or understand by including 2 or more of the following pieces of information:

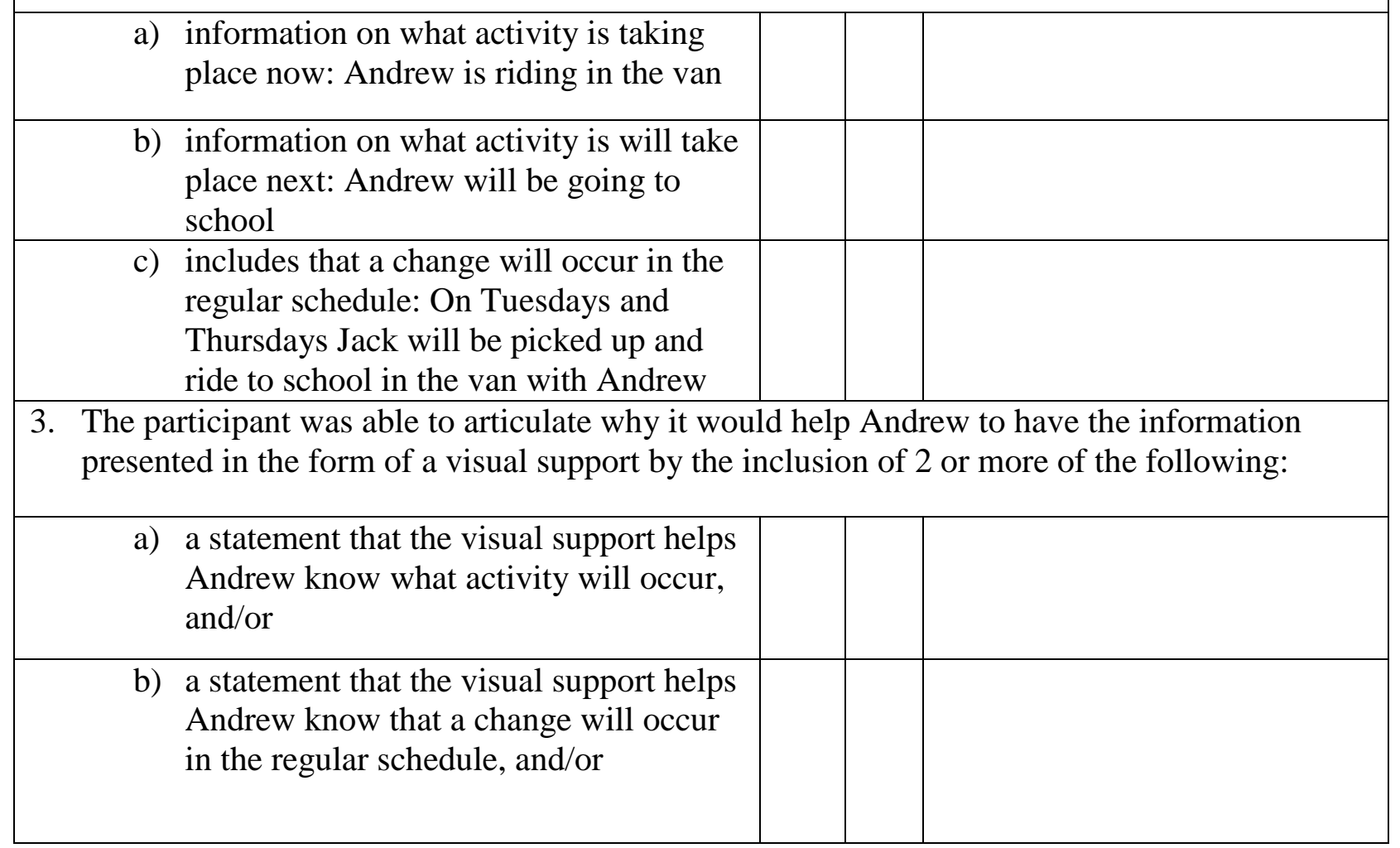




\begin{tabular}{|l|l|l|l|}
\hline c) $\begin{array}{l}\text { a statement that the visual support } \\
\text { might help reduce Andrew's frustration } \\
\text { and/or anxiety, and/or }\end{array}$ & & & \\
\hline d) $\begin{array}{l}\text { a statement that Andrew relies on the } \\
\text { use of a visual support for other } \\
\text { transitional activities (e.g., morning } \\
\text { routine) }\end{array}$ & & & \\
\hline
\end{tabular}

\section{Additional evaluative information:}

A. Did the participant include any other additional information not included within the information on the visual support checklist (Please Circle One)?

\section{Yes or No}

(If the answer is No, then please go to the Summative Comments (D) located at the end of the evaluative form.)

B. If the answer to question $\mathrm{A}$ is Yes, then what additional information did the participant relay or provide (please write in the answer on the lines provided):

C. If the answer to question $\mathrm{A}$ is yes, then was the additional information an example of positive practice for children with autism (Please Circle One)?

\section{Yes or No}

D. Summative comments: 
Adapted from the Implementation Checklist for Visual Support on the Ocali website for educators to be used for parents (see following for portion of the original checklist):

Hume, K., \& Smith, S. (2009). Implementation checklist for visual supports. Chapel Hill, NC: The National Professional Development Center on Autism Spectrum Disorders, Frank Porter Graham Child Development Institute, The University of North Carolina.

Figure 9. Visual Support Expert Checklist 


\section{Module: Visual Supports}

\section{Implementation Checklist for Visual Supports}

Note: Implementation guidelines for visual schedules, to-do lists, transition supports, community supports, and supports outside the classroom can be found on the Implementation Checklist for Visual Schedules. Implementation guidelines for visual boundaries can be found on the Implementation Checklist for Visual Boundaries.

Hume, K., \& Smith, S. (2009). Implementation checklist for visual supports. Chapel Hill, NC: The National Professional Development Center on Autism Spectrum Disorders, Frank Porter Graham Child Development Institute, The University of North Carolina.

Instructions: The Implementation Checklist includes steps for the development and implementation of visual supports. Please complete all of the requested information including the site and state, individual being observed/interviewed, and the learner's initials. To assure that a practice is being implemented as intended, an observation is a/ways preferable. This may not always be possible. Thus, items may be scored based on observations with the implementer, discussions and/or record review as appropriate. Within the table, record a 2 (implemented), 1 (partially implemented), 0 (did not implement), or NA (not applicable) next to each step observed to indicate to what extent the step was implemented/addressed during your observation. Use the last page of the checklist to record the target skill, your comments, whether others were present, and plans for next steps for each observation.

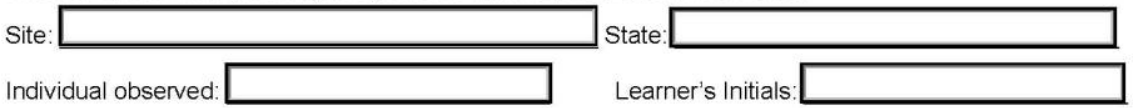

Skills below can be implemented by a practitioner, parent, or other team member

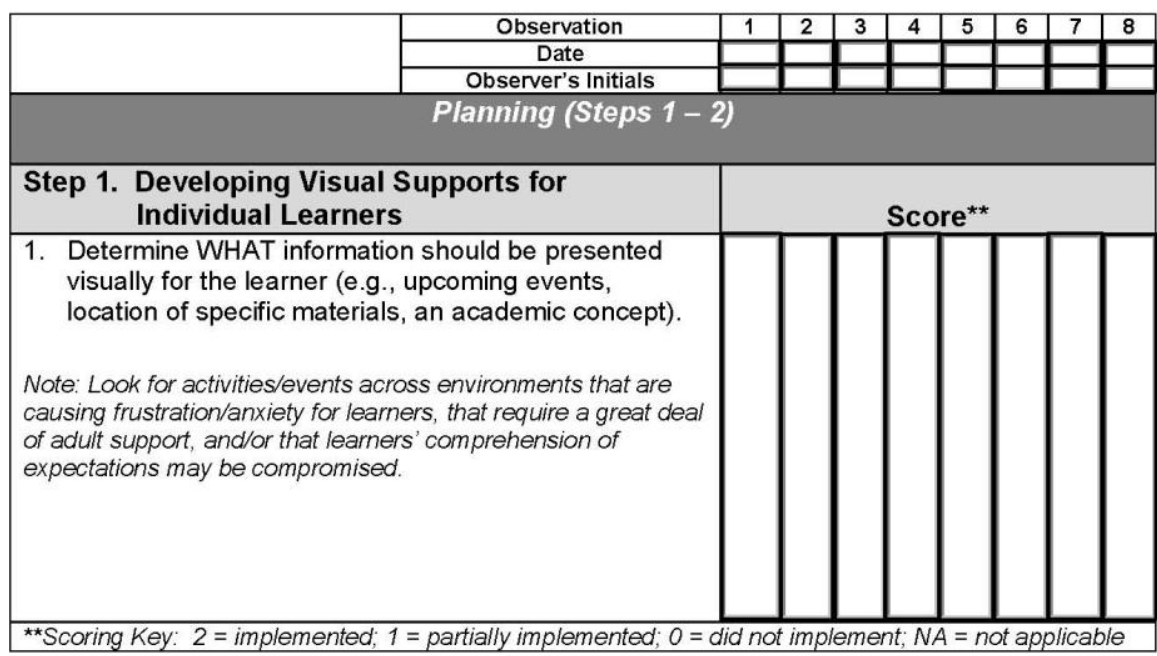

Visual Supports: Implementation Checklist

National Professional Development Center on ASD

Page 1 of 7

$10 / 2010$ 
Module: Visual Supports

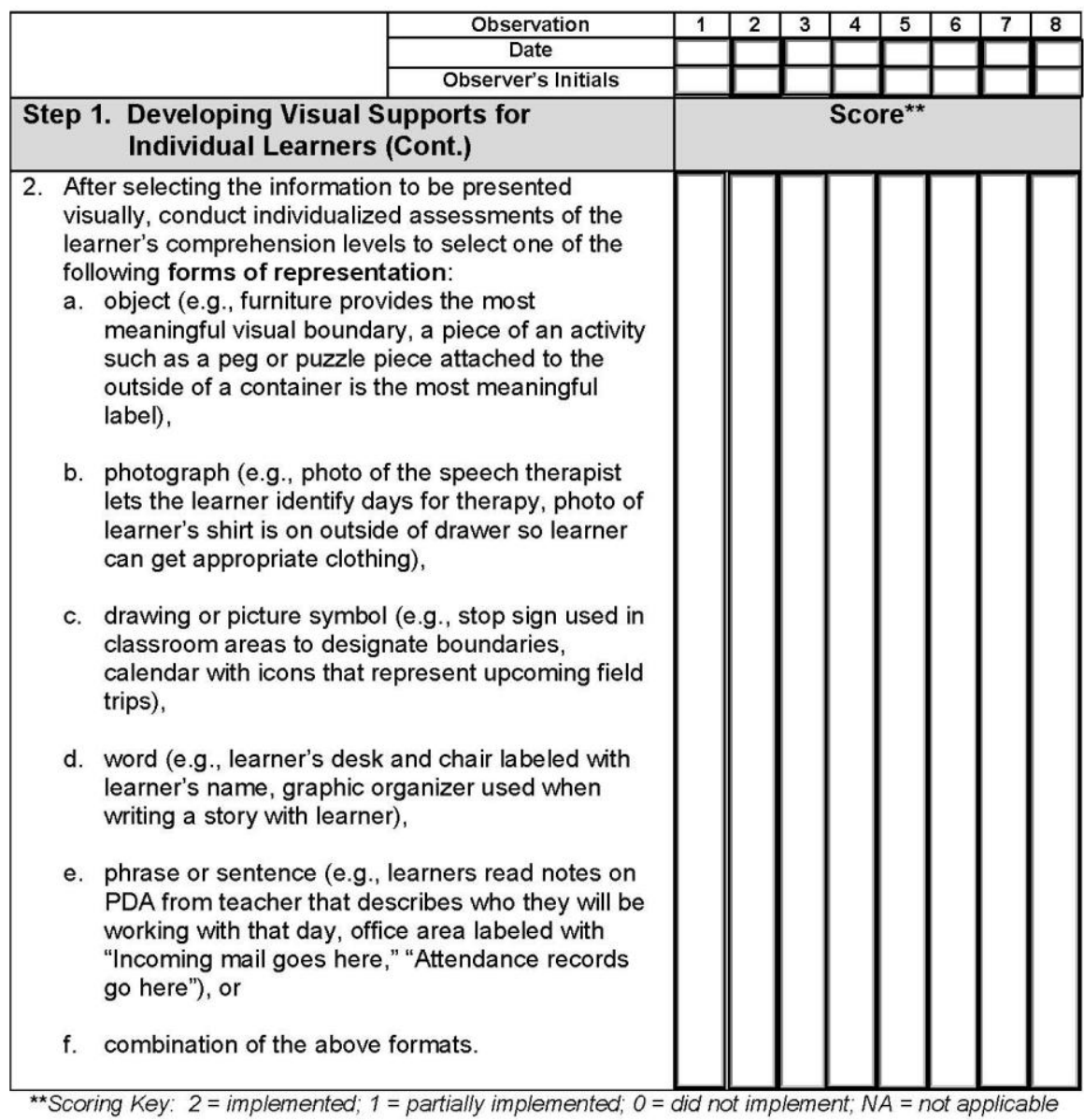




\section{PARENT SATISFACTION SURVEY}

Please complete and return in the prepaid envelope. Thank You!!

Name of Participant:

Please complete the Parent Satisfaction Survey by rating all statements numbers 1-7.

Please circle only one number for any given question.

Please provide any additional information in the space provide after each statement as to why

you provided the rating.

Please fill out and send back within one week of receiving survey.

1= strongly disagree, $4=$ neither agree nor disagree, $7=$ strongly agree

$\begin{array}{lllllllll}\text { 1. The online training } & 1 & 2 & 3 & 4 & 5 & 6 & 7\end{array}$ modules were clear and understandable

Why provided rating?

2. The format of the program 1 was appropriate (selfdirected, online training)

Why provided rating?

3. The unlimited access to the 1

2

3

4

5

6

7 online training was convenient. 
Why provided rating?

4. I feel that I gained knowledge of visual supports.

Why provided rating?

5. I feel this is a good way to

1

2

3

$\begin{array}{lll}4 & 5 & 6\end{array}$

7 learn information to help me meet my child's needs.

Why provided rating?

6. The online training

1

2

3

4

5

6

7 modules were easy to use.

Why provided rating? 
7. I enjoyed this online training program.

Why provided rating?

\section{PLEASE COMPLETE AND RETURN IN THE PREPAID ENVELOPE. THANK YOU!!}

Adapted from the Parent Satisfaction Survey in:

Ingersoll, B., \& Dvortcsak, A. (2006). Including parent training in the early childhood special education curriculum for children with autism spectrum disorders. Journal of Positive Behavior Interventions, 8(2), 79-87.

Figure 10. Parent Satisfaction Survey 
Table 7

Table of Participant and Researcher Timeline

\begin{tabular}{|c|c|c|c|c|}
\hline & Step 1 & Step 2 & Step 3 & Step 4 \\
\hline Researcher Action(s) & $\begin{array}{l}\text { Find participants } \\
\text { Have experts revise } \\
\text { rubric }\end{array}$ & $\begin{array}{l}\text { Prior to initiation of } \\
\text { parent training Send } \\
\text { packet Number } 1\end{array}$ & $\begin{array}{l}\text { Once receive forms } \\
\text { from step 2, send } \\
\text { packet Number } 2\end{array}$ & $\begin{array}{l}\text { Once receive self- } \\
\text { monitoring checklist } \\
\text { send packet Number } \\
3\end{array}$ \\
\hline Document(s) & $\begin{array}{l}>\text { Advertisement for } \\
\text { Participants }\end{array}$ & $\begin{array}{l}\text { Packet } 1 \text { Contains: } \\
>\text { Participant Cover } \\
\text { Letter } \\
>\text { Participant } \\
\text { Demographic Form } \\
>\text { Pretest }\end{array}$ & 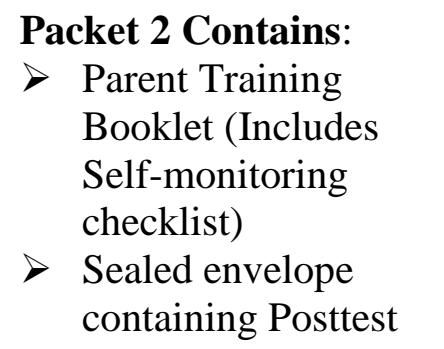 & $\begin{array}{l}\text { Packet } 3 \text { Contains: } \\
>\text { Visual Support } \\
\text { Activity } \\
>\text { Pics for Pecs } \\
\text { software } \\
>\text { Parent Satisfaction } \\
\text { Form }\end{array}$ \\
\hline Participants Action(s) & $\begin{array}{l}\text { 1. Contact researcher } \\
\text { either by email or } \\
\text { phone to state } \\
\text { interest in study }\end{array}$ & $\begin{array}{l}\text { 1. Read Cover Letter } \\
\text { 2. Complete Participant } \\
\text { Demographic Form } \\
\text { 3. Complete Pretest } \\
\text { 4. Send completed } \\
\text { Participant } \\
\text { Demographic Form } \\
\text { and Pretest to the } \\
\text { researcher in a } \\
\text { prepaid envelope } \\
\text { within } 5 \text { days of } \\
\text { receiving }\end{array}$ & $\begin{array}{l}\text { 1. Complete online } \\
\text { module using self- } \\
\text { monitoring checklist } \\
\text { 2. Send completed } \\
\text { checklist to } \\
\text { researcher in prepaid } \\
\text { envelope within } 7 \\
\text { days of receiving } \\
\text { 3. Next, Open up } \\
\text { Posttest sealed } \\
\text { envelope and } \\
\text { complete/Return } \\
\text { Posttest in prepaid } \\
\text { envelope in } 5 \text { days of } \\
\text { completing training }\end{array}$ & 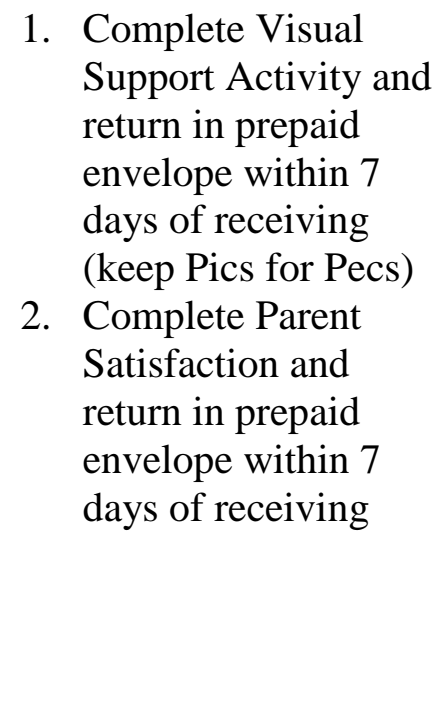 \\
\hline
\end{tabular}


Appendix C 
Table 8

Table of Peer-Reviewed Articles Published Between 2001 and 2010

\begin{tabular}{|c|c|c|c|c|}
\hline Study (Year) & Purpose/Method/Setting & Participants & Design & Main Findings \\
\hline $\begin{array}{l}\text { Brookman \& Frazee } \\
\text { (2004) }\end{array}$ & $\begin{array}{l}\text { Parent training PRT utilizing both } \\
\text { clinician led and parent led parent- } \\
\text { clinician partnership (Home-based } \\
2 \text { children and Facility-based } 1 \\
\text { child) }\end{array}$ & $\begin{array}{l}3 \text { children with } \\
\text { autism their mothers }\end{array}$ & $\begin{array}{l}\text { Repeated reversal } \\
\text { design }\end{array}$ & $\begin{array}{l}\text { Parent led partnership } \\
\text { demonstrate lower parental } \\
\text { stress and higher parental } \\
\text { confidence; children higher } \\
\text { level of responding and } \\
\text { engagement with the parent } \\
\text { led partnership }\end{array}$ \\
\hline $\begin{array}{l}\text { Coolican, Smith \& } \\
\text { Bryson (2010) }\end{array}$ & $\begin{array}{l}\text { Brief parent training PRT to meet } \\
\text { needs of parents on long waiting } \\
\text { list for services (Home-based and } \\
\text { Facility-based) }\end{array}$ & $\begin{array}{l}8 \text { families; } 5 \text { mothers } \\
3 \text { fathers; children } \\
\text { with autism ages } 2-5\end{array}$ & $\begin{array}{l}\text { Non-concurrent } \\
\text { multiple baseline } \\
\text { across participants }\end{array}$ & $\begin{array}{l}\text { Increase child functional } \\
\text { verbal utterances; decrease } \\
\text { disruptive behavior; parent } \\
\text { report positive satisfaction } \\
\text { child communication }\end{array}$ \\
\hline $\begin{array}{l}\text { Elder, Valcante, Won } \\
\text { \& Zylis (2003) }\end{array}$ & $\begin{array}{l}\text { Program } 12 \text { weeks: Intervention } \\
\text { train father imitating animation/ } \\
\text { expectant waiting (Home-based) }\end{array}$ & $\begin{array}{l}4 \text { children with } \\
\text { autism and parents } \\
\text { representing } 4 \text { ethnic } \\
\text { groups }\end{array}$ & $\begin{array}{l}\text { Multiple-baseline } \\
\text { across participants }\end{array}$ & $\begin{array}{l}\text { Three out of four families } \\
\text { noted increase in positive } \\
\text { father/child interactions }\end{array}$ \\
\hline
\end{tabular}




\begin{tabular}{|c|c|c|c|c|}
\hline Study (Year) & Purpose/Method/Setting & Participants & Design & Main Findings \\
\hline $\begin{array}{l}\text { Ingersoll \& Dvortcsak } \\
\text { (2006) }\end{array}$ & $\begin{array}{l}9 \text { wk parent training on naturalistic } \\
\text { techniques to increase social and } \\
\text { communicative interactions } \\
\text { (Facility-based) }\end{array}$ & $\begin{array}{l}9 \text { families; child } \\
\text { with autism ages } 3- \\
4 \text {; parent age } 20-40\end{array}$ & Survey/quiz & $\begin{array}{l}\text { Posttest show increase in } \\
\text { parent knowledge on taught } \\
\text { procedures }\end{array}$ \\
\hline $\begin{array}{l}\text { Kashinath, Woods \& } \\
\text { Goldstein (2006) }\end{array}$ & $\begin{array}{l}\text { Identify routines, teach } \\
\text { strategies/Parent implement target } \\
\text { strategy (Home-based) }\end{array}$ & $\begin{array}{l}5 \text { children with } \\
\text { autism } 33-65 \\
\text { months; mothers } \\
\text { ages } 26-45\end{array}$ & $\begin{array}{l}\text { Multiple baseline } \\
\text { across teaching } \\
\text { strategies }\end{array}$ & $\begin{array}{l}\text { Parents increase use } \\
\text { teaching strategies; child } \\
\text { increase communication }\end{array}$ \\
\hline $\begin{array}{l}\text { Koegel, Symon, \& } \\
\text { Koegel (2002) }\end{array}$ & $\begin{array}{l}\text { Parent training PRT at autism } \\
\text { center } 5 \text { consecutive days } / 25 \mathrm{hr} \\
\text { total training (Facility-based) }\end{array}$ & $\begin{array}{l}5 \text { families distantly } \\
\text { located from autism } \\
\text { center }\end{array}$ & $\begin{array}{l}\text { Multiple baseline } \\
\text { across participants }\end{array}$ & $\begin{array}{l}\text { Parent could implement } \\
\text { PRT techniques after } \\
\text { training }\end{array}$ \\
\hline $\begin{array}{l}\text { Laugeson, Frankel, } \\
\text { Mogil \& Dillon } \\
\text { (2009) }\end{array}$ & $\begin{array}{l}\text { Increase socialization by parent } \\
\text { assisted social skills training } \\
\text { (Facility-based) }\end{array}$ & $\begin{array}{l}33 \text { teens ages } 13-17 \\
\text { and their parents }\end{array}$ & $\begin{array}{l}\text { Randomized } \\
\text { control study/ } \\
\text { delayed treatment } \\
\text { control group }\end{array}$ & $\begin{array}{l}\text { Treatment group had overall } \\
\text { improvement in teen social } \\
\text { skills when compared to } \\
\text { control group }\end{array}$ \\
\hline Moes \& Frea (2002) & $\begin{array}{l}\text { Conduct FBA; parent training to } \\
\text { provide child with functional } \\
\text { communication (Home-based) }\end{array}$ & $\begin{array}{l}3 \text { families children } \\
\text { with autism age of } \\
\text { all children } 3 \text { yrs old }\end{array}$ & $\begin{array}{l}\text { Multiple-baseline } \\
\text { across participants }\end{array}$ & $\begin{array}{l}\text { Decreased problem behavior } \\
\text { and increase functional } \\
\text { communication }\end{array}$ \\
\hline $\begin{array}{l}\text { Nefdt, Koegel, Singer } \\
\& \text { Gerber }(2010)\end{array}$ & $\begin{array}{l}\text { Self-directed learning; parent } \\
\text { implementation PRT utilizing } \\
\text { video instruction/ training manual } \\
\text { (Home-based) }\end{array}$ & $\begin{array}{l}\text { Primary caretakers } \\
\text { of } 27 \text { children with } \\
\text { autism }\end{array}$ & $\begin{array}{l}\text { Randomized } \\
\text { clinical trial }\end{array}$ & $\begin{array}{l}\text { Increased parent /child } \\
\text { interactions and child } \\
\text { increased verbalization }\end{array}$ \\
\hline
\end{tabular}




\begin{tabular}{llll}
\hline \multicolumn{1}{c}{ Study (Year) } & \multicolumn{1}{c}{ Purpose/Method/Setting } & \multicolumn{1}{c}{ Participants } & \multicolumn{1}{c}{ Design } \\
\hline $\begin{array}{l}\text { Nunes \& Hanline } \\
(2007)\end{array}$ & $\begin{array}{l}\text { Parent training on instructional } \\
\text { techniques (Home-based) }\end{array}$ & $\begin{array}{l}4 \text { yr old boy with } \\
\text { autism and mother } \\
\text { of boy }\end{array}$ & $\begin{array}{l}\text { Multiple baseline } \\
\text { across play and care } \\
\text { giving routines }\end{array}$
\end{tabular}

Peishi (2008)

Reagon \& Higbee (2009)

Schertz \& Odom (2007)

Seung, Ashwell, Elder $\&$ Valcante (2006)
Parent training on ABA, TEACCH and naturalistic strategies to prepare parent for becoming primary service provider (Homebased and Facility-based)

Parent trained use script development and fading procedures, pre-teaching skills, modeling, prompts, and feedback (Home-based)

Parent training joint attention strategies (Home-based)

Training parents expectant waiting/imitating with animation; measured difference between mother and father (Home-based)
27 families with children with autism

Randomized control study/ delayed treatment control group

3 children with autism ages 2,3 , and 6 and their parents

3 parents of toddlers with autism

Multiple-baseline across participants

8 children ages 4-7 Multiple baseline and their families

Multiple baseline across participants
Caregiver increase use 2 teaching strategies across routines; increase child initiations, responses, and use of AAC

Parent in training group more responsive to child needs and more accepting of child

Children acquired 3-scripted initiation; demonstrate parents ability to implement language interventions with their children

Parent overall satisfaction with intervention; positive child gains in joint attention and maintenance of learned behaviors

No difference in learning of trained skills between mother and father; children showed improvement in 1 word utterances 


\section{Study (Year)}

Solomon, Ono,

Timmer \& Goodlin-

Jones (2008)

Solomon, Necheles, Ferch \& Bruckman (2007)

Stahmer \& Gist (2001)

Symon (2005)

Tarbox, Schiff \&

Najdowski (2010)

Vismara, Colombi, \& Rogers (2009) Purpose/Method/Setting

Parent trained parent/child interaction therapy (Facilitybased)

Parent training utilizing Floortime model (Home-based)

12 wk parent education on PRT; half the parents participated in an additional 12 wk parent support group (Home-based)

Parent training PRT at a training center for 5 consecutive day $/ 25 \mathrm{hr}$ total training (Facility-based)

Mother taught how to implement plan to decrease food selectivity by increasing food intake, and alter escape extinction (Homebased)

$12 \mathrm{wk} / 1 \mathrm{hr}$ per week brief parent training in Early Start Denver Model and PRT to meet barriers to service (Facility-based)
68 children ages 1.5- Clinical trial 6 and their families

Participants Design

Nineteen males with Waitlist control autism ages 5-12 group design

22 families enrolled on a parent education program

Pre-post group treatment design

3 families each include mom as primary care, child with autism, and a significant caregiver

$3 \mathrm{yr}$ old boy with autism and mother

8 families of children with autism under 36 months old
Non-concurrent multiple-baseline design

\section{$\mathrm{ABAB}$ design}

Non-concurrent multiple-baseline

\section{Main Findings}

Parent report found child's behavior less distressing; child improvement adaptive functioning, transitions, and willingness to share items High parent training satisfaction and child developmental gains

Parents in support group perform significantly better meeting technique criteria; higher skilled parent; child gains in verbalization skills

\section{Parent successfully learn PRT and train another of their child's caregivers; child significant improvement}

Goal achieved and child significant reduction in food selectivity

Parent learn skill; child increase functional verbal utterances and imitative behaviors 


\section{Study (Year)}

Whittingham,

Sofronoff, Sheffield \&

Sanders (2009)

\section{Purpose/Method/Setting}

Parent training in positive

parenting principles and use of

Social Stories/Comic Strip

Conversations by Carol Grey

(Facility-based)

\section{Participants}

59 families of

children with

autism; 29 treatment

group; 30 wait-list

group; children ages

2-9
Design

Randomized

control trial

w/mixed within-

between-subjects

design \&wait-list

control group
Main Findings

Trained parent less over reactive to their child's behavior and less verbose when working with their child then wait group; overall parent satisfaction; significant improvement child behavior 
54 Manor Road

Jennifer L. Suppo

Donora, PA 15033

724-396-1133

delsuppo@yahoo.com

\section{Education:}

Doctor of Education - Special Education

West Virginia University- Morgantown, WV

Summer 2012

GPA: $4.0 / 4.0$

Applied Behavioral Analysis Certificate

Florida Institute of Technology - Melbourne, FL

Spring 2010-Present

Working on requirements for Board Certified Behavior Analyst ${ }^{\circledR}$ (BCBA)

Master of Education Degree, Major: Mentally/Physically Handicapped

California University of Pennsylvania - California, PA

December 2008

GPA: $3.97 / 4.00$

Corporate Law Paralegal Post-Bachelor's Certificate

(Approved by the American Bar Association)

Duquesne University - Pittsburgh, PA

June 1995

GPA: $3.84 / 4.00$

\section{Bachelor of Arts Degree, Major: Political Science/Pre-law}

California University of Pennsylvania- California, PA

May 1994

GPA 3.44/4.00

\section{Honors and Awards:}

Full Scholarship with living stipend for Doctoral Study at

West Virginia University 2010-2012

Presidential Scholar Graduate, California University of PA 2008

Conductor Award Nominee from ABOARD (Advisory Board on 2005

Autism and Related Disorders)

Presidential Scholar Undergraduate, California University of PA 1993 \& 1994

Dean's List, California University of PA 1991-1994

\section{Professional Certification:}

K-12 Multi-categorical Special Education (Pennsylvania)

\section{University Teaching Experience:}

\section{Adjunct Professor- West Virginia University, Morgantown, WV: Spring 2012}

Educational Intervention: Autism (online): Graduate course is designed to prepare prospective and practicing special educators to recognize characteristics of autism spectrum disorders and content is delivered to students using ECampus and Live Wimba classroom

Adjunct Professor- West Virginia University, Morgantown, WV: Fall 2011

Contemporary Issues in Special Education (campus course): Course is designed to provide students with special education practices and principles: Deliver content to students on campus and utilizing ECampus 
Internship - West Virginia University, Morgantown, WV: Spring 2011

Educational Intervention: Autism (online): Course is designed to prepare prospective and practicing special educators to recognize characteristics of autism spectrum disorders: Delivered content to students using ECampus and Live Wimba classroom

Internship - West Virginia University, Morgantown, WV: Spring 2011

Behavior Supports for Students with Special Needs (campus course): Course provides students with an introduction to the application of applied behavioral analysis.

\section{Guest Lecture:}

SPED 304 Contemporary Issues in Special Education, Working with Parents and Families: Fall 2011 SPED 304 Contemporary Issues in Special Education, Working with Parents and Families: Spring 2012

\section{School Teaching Experience:}

Special Education Teacher - Life Skills Support/Autistic Support: 2009- 2010

Bentworth Middle School, Bentleyville, PA

- Implemented behavioral money management system

- Initial classroom setup and selection of classroom curriculum

- Differentiated instruction in math, reading, science, and social studies including use of MayerJohnson Boardmaker, Promethean Board, and Proloquo 2 Go

- Taught social skills class

- Initiated and implemented peer buddy system with local girl scout troop

- Taught pre-vocational skills

Special Education Teacher - Autistic Support: 2008 - 2009

Intermediate Unit One Classroom - Bentworth Middle School, Bentleyville, PA

- Initial classroom setup

- Coordinated with parents, teachers, paraprofessionals, and other service providers

- Upheld a solid classroom management plan

- Taught multi-levels of Direct Instruction Math, adapted social studies and science

- Employed diverse techniques to promote an active learning atmosphere, including individualized instruction, problem-solving techniques, and small-group work

- Incorporated flexibility within the classroom addressing students needs through special accommodations

Graduate Assistant - Department of Special Education: 2008

California University of Pennsylvania, California, PA

- Helped organize and execute the university's first autism conference with over 600 attendees

- Managed over sixty student volunteers for the autism conference

- Assisted in obtaining speakers and vendors

- Helped create the universities first autism solution focused legislative meeting

\section{Publications:}

Suppo, J. L., \& Floyd, K. (In press). Parent training for families who have children with autism: A review of the literature. Rural Special Education Quarterly.

Suppo, J. L., \& Mayton, M. R. (In press). A portable potty plan for children with autism. Young Exceptional Children. 


\section{Presentations:}

Suppo, J. L. (May, 2012). A Portable Potty Plan for Children with Autism. Presenter California University of Pennsylvania Autism Conference, California, PA.

Keramidas, C., Suppo, J. L., \& Harman, L. (March, 2011). Should we change how we teach online? Students and their online preferences. ACRES National conference, Albuquerque, NM.

Suppo, J. L. (December, 2010). Community supports for children with autism. Invited Speaker at Cleveland State University Autism Workshop, Cleveland, OH.

Suppo, J. L. (October, 2010). Here we go... Overcoming challenges presented when out in the community. Presenter West Virginia University Autism in Focus Conference. Morgantown, WV.

Suppo, J. L. (March, 2009). Out and about: Overcoming challenges presented when going out in the community. Invited Speaker at California University of Pennsylvania ASD Life Transitions and Partnership, California, PA.

Suppo, J. L. (March 2008). Out and about: Overcoming challenges presented when going out in the community. Presenter California University of Pennsylvania Autism Conference, California, PA.

Co-director

\section{Grants:}

Mitchem, K., \& Suppo, J. L. (2008-2009) Multimedia Case-Based Instruction on Autism Spectrum Disorders. PASSHE Grant.

Co-director

Mitchem, K., \& Suppo, J. L. (2007-2008) PEP (Parents, Educators, Providers) Rally for

Autism Spectrum Disorders. California University of Pennsylvania Professional Development Grant.

\section{Professional Service:}

Special Needs Director (2011-present) Hot Cheer-Special Needs Competitive Cheerleading Team Guest reviewer (10/11) Rural Special Education Quarterly

Guest reviewer (09/11) Teaching Exceptional Children

Serve on Expert Panel for federally funded grant (April 2010) Electronic Performance Support for School-wide Positive Behavior Support

Serve on Expert Panel for federally funded grant (Spring 2009) Electronic Performance Support - Kids Tools

\section{Professional Affiliations:}

ABOARD's (Advisory Board on Autism and Related Disorders) Autism Connection of Pennsylvania ACRES (American Council on Rural Special Education)

C.E.C (Council for Exceptional Children)

NEA (National Education Association)

PSEA (The Pennsylvania State Education Association) 